\title{
Tetramethylpyrazine: A Review of Its Antitumor Potential and Mechanisms
}

OPEN ACCESS

Edited by:

Nand K. Roy,

Case Western Reserve University, United States

Reviewed by:

Mukerrem Betul Yerer Aycan,

Erciyes University, Turkey

Xiaonan Gao,

Shandong Normal University, China

Asieh Heirani-Tabasi,

Tehran University of Medical

Sciences, Iran

${ }^{*}$ Correspondence: Jing Kong

kongjing1998@163.com

Specialty section:

This article was submitted to Pharmacology of Anti-Cancer Drugs,

a section of the journal

Frontiers in Pharmacology

Received: 25 August 2021 Accepted: 18 November 2021

Published: 16 December 2021

Citation:

Yang S, Wu S, Dai W, Pang L, Xie Y,

Ren $T$, Zhang $X, B i S$, Zheng $Y$, Wang J, Sun Y, Zheng Z and Kong J (2021) Tetramethylpyrazine: A Review

of Its Antitumor Potential and Mechanisms.

Front. Pharmacol. 12:764331. doi: 10.3389/fphar.2021.764331

\begin{abstract}
Shaojie Yang ${ }^{1}$, Shuodong $W_{u^{1}}$, Wanlin Dai ${ }^{2}$, Liwei Pang ${ }^{1}$, Yaofeng Xie ${ }^{3}$, Tengqi Ren ${ }^{1}$, Xiaolin Zhang ${ }^{1}$, Shiyuan $\mathrm{Bi}^{1}$, Yuting Zheng ${ }^{1}$, Jingnan Wang ${ }^{1}$, Yang Sun ${ }^{1}$, Zhuyuan Zheng ${ }^{1}$ and Jing Kong ${ }^{1 *}$
\end{abstract}

\begin{abstract}
${ }^{1}$ Biliary Surgery (2nd General) Unit, Department of General Surgery, Shengjing Hospital of China Medical University, Shenyang, China, ${ }^{2}$ Innovation Institute of China Medical University, Shenyang, China, ${ }^{3}$ Department of Cardiology, Shengjing Hospital of China Medical University, Shenyang, China
\end{abstract}

Cancer remains a major public health threat. The mitigation of the associated morbidity and mortality remains a major research focus. From a molecular biological perspective, cancer is defined as uncontrolled cell division and abnormal cell growth caused by various gene mutations. Therefore, there remains an urgent need to develop safe and effective antitumor drugs. The antitumor effect of plant extracts, which are characterized by relatively low toxicity and adverse effect, has attracted significant attention. For example, increasing attention has been paid to the antitumor effects of tetramethylpyrazine (TMP), the active component of the Chinese medicine Chuanqiong, which can affect tumor cell proliferation, apoptosis, invasion, metastasis, and angiogenesis, as well as reverse chemotherapeutic resistance in neoplasms, thereby triggering antitumor effects. Moreover, TMP can be used in combination with chemotherapeutic agents to enhance their effects and reduce the side effect associated with chemotherapy. Herein, we review the antitumor effects of TMP to provide a theoretical basis and foundation for the further exploration of its underlying antitumor mechanisms and promoting its clinical application.

Keywords: tetramethylpyrazine, ligustrazine, antitumor, apoptosis, metastasis, angiogenesis, chemotherapy, multidrug resistant

\section{INTRODUCTION}

Cancer remains a global public health threat caused by numerous factors, including aging, smoking (Bach, 2009; Thun et al., 2013), unhealthy dietary habits (Xiao et al., 2011), environmental pollution (Raaschou-Nielsen et al., 2013), lack of activity, and obesity (Wang et al., 2012; Islami et al., 2017). According to the global disease burden statistics published by the Washington University, cancerrelated deaths account for approximately $15 \%$ of all deaths (Global Burden of Disease, Mortality and Causes of Death Collaborators, 2015). The Global Cancer Observatory 2020 database reported an estimated 19,292,789 cancer cases and 9,958,133 cancer-related deaths in 2020. Female breast cancer has surpassed lung cancer as the most common cancer, with an estimated 2,261,419 new cases, accounting for $11.7 \%$ of all cancer cases, followed by lung (11.4\%), colorectal (10.0\%), prostate (7.3\%), and gastric cancers (5.6\%). Lung cancer remained the leading cause of death due to cancer, with an estimated $1,796,144$ deaths in 2020 , accounting for $18.0 \%$ of all cancer-related deaths, followed by colorectal cancer (9.4\%), liver cancer (8.3\%), gastric cancer (7.7\%), and female breast cancer (6.9\%). The incidence of cancer and its associated mortality present significant variations according to region and sex (Sung et al., 2021). Compared with the 2020 estimates, new cases and 


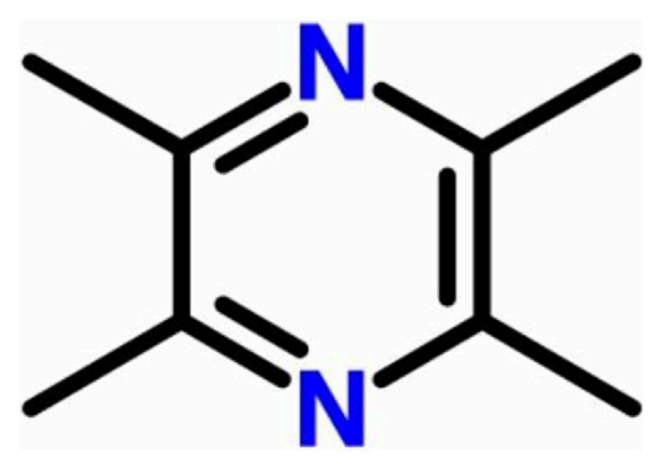

FIGURE 1 | Chemical structure of tetramethylpyrazine.

deaths in 2040 are expected to increase by $49 \%$ and $62 \%$, respectively. In the next 20 years, the burden of cancer will continue to increase (Cao et al., 2021).

The Chinese medicine Chuanqiong is the dry rhizome of the plant Ligusticum chuanxiong Hort, which belongs to the family Apiaceae. It has a pungent flavor with a unique aroma and is beneficial for the liver, gallbladder, and pericardium meridian. Chuanqiong has a high medicinal value with respect to activating blood circulation to dissipate blood stasis. The main components of Chuanqiong include alkaloids, phenols, and volatile oil (Wen et al., 2021). Among them, the main alkaloid component is tetramethylpyrazine (TMP) (Figure 1), also known as ligustrazine (chemical name: 2,3,5,6tetramethylpyrazine; pyrazine; molecular formula: $\mathrm{C}_{8} \mathrm{H}_{12} \mathrm{~N}_{2}$ ). TMP is an effective monomer obtained from the alkaloid of Chuanqiong and is also the main active substance in Chuanqiong. Previous studies have shown that TMP can exert antithrombosis, antiplatelet agglutination, antioxidation, and anti-ischemia reperfusion injury effects, improve microcirculation (Zou et al., 2018; Li et al., 2019; Zhou et al., 2020), and is widely used in various traumatic conditions and surgical treatments (Li et al., 2006; Yan et al., 2019). Additionally, TMP is used in the treatment of renal dysfunction (Sun et al., 2020), coronary heart disease (Wang et al., 2017), diabetes (Jiao et al., 2019), and cerebral infarction (Xu et al., 2017). At present, studies on the pharmacological role and clinical applications of TMP are very broad, and researchers are continuing to gain a deeper understanding of its characteristics.

In this review, we summarize the antitumor properties and potential mechanisms underlying the role of TMP in various tumors based on in vitro and in vivo studies. In addition to affecting the malignant biological behavior of tumor cells, TMP has protective effects on corresponding nontumor normal tissues. TMP can also be combined with chemotherapeutic agents to strengthen the damaging effects on tumors and can reduce the poisonous adverse effects caused by chemotherapeutic drugs, such as cardiac toxicity (Yang et al., 2019) and kidney toxicity (Michel and Menze, 2019). We compile these scientific pieces of evidence in this review to promote future research into the clinical application of TMP and further explore the potential treatment targets of TMP. We searched for almost all published papers related to the treatment of tumors with TMP in PubMed (https://pubmed.ncbi.nlm.nih.gov/) and summarized all the reports in this review. There is a large amount of research on
TMP published in databases in Asia. Since these articles were not published in English, data provided in them remain unknown to researchers in other parts of the world.

\section{OVERVIEW OF TETRAMETHYLPYRAZINE}

TMP has traditional significance in the treatment of ischemic cerebrovascular disease (Li et al., 2015) and in a wide range of other clinical applications. TMP, in combination with other drugs, is used widely in clinical practice. In recent years, studies have shown that TMP has various effects, including blood glucose and lipid regulation, hepatic protection, and mitigates inflammation and vascular endothelial cell injury (Guo et al., 2016), and has enormous potential for future clinical application. TMP is also widely used in basic clinical treatment, and researchers have very broadly studied various aspects of it, such as its sedative and analgesic effects (Liang et al., 2005; Gao et al., 2008), antithrombotic effects (Cai et al., 2014), protection against ischemia reperfusion injury (Qian et al., 2014; Zhang et al., 2014; Zhang et al., 2018), and effects on blood vessels (Shan Au et al., 2003; Xu et al., 2014).

\section{ANTITUMOR MECHANISM UNDERLYING THE EFFECTS OF TETRAMETHYLPYRAZINE IN MULTIPLE ORGANS}

TMP has shown antitumor effects on various tumor types (Figure 2), including brain glioma (Cai et al., 2014), breast (Fan et al., 2021), prostate (Zhou et al., 2020), and lung cancers (Huang et al., 2018). Tumor growth can be reversed by applying different concentrations of TMP to tumor cells. Researchers have developed in vitro strategies for assessing the dosage, efficacy, and potential molecular mechanisms underlying the effects of TMP in different tumor cells (Fu et al., 2008; Huang et al., 2018; Zhou et al., 2020). TMP exhibits various antitumor effect on different tumor cells. TMP regulates various molecular signal pathways to alter the malignant biological behavior of tumor cells, including proliferation (Fu et al., 2008), cell cycle regulation (Yu et al., 2012), apoptosis (Cheng et al., 2007), invasion ( $\mathrm{Xu}$ et al., 2018), metastasis (Fu et al., 2008), and angiogenesis (Jia et al., 2016). TMP also exhibits antiproliferative and antiangiogenic potential in a variety of in vivo models including a xenograft mouse model (Yu et al., 2012) and other experimental animal models (Fu et al., 2008). Overall, TMP has shown promising potential as an antitumor drug. In this review, we elaborate on the resistance of tumors to TMP according to body systems and the significant protection of organs around the tumor.

\subsection{Brain and nervous system}

Glioma is the most common tumor of the central nervous system that originates in glial cells. Over the past 30 years, the incidence of glioma has increased at a rate of $1 \%-2 \%$ per year (Chen et al., 


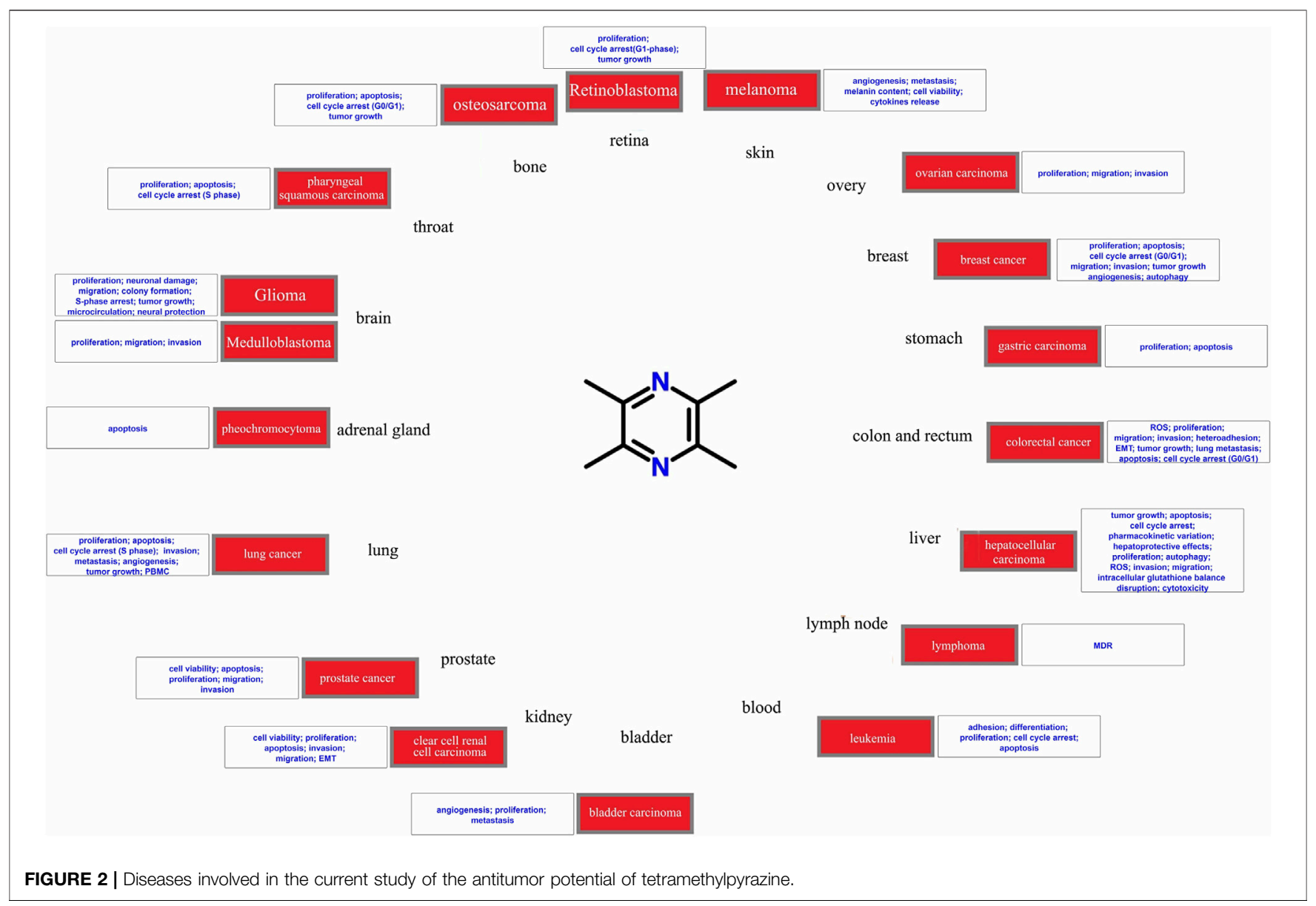

2020). At present, treatment modalities available for glioma include surgery, chemotherapy, and radiotherapy; gene therapy and immunotherapy have also been actively studied. However, the overall efficacy is not ideal (Eslahi et al., 2021). Fu et al. (2008) investigated the possible therapeutic efficacy of TMP against a rat glioma cell line (C6) and gliomas transplanted into rat brains. The authors found that TMP can suppress glioma activity, including growth, and protect neurons against glioma-induced excitotoxicity. C-X-C chemokine receptor type 4 (CXCR4), initially discovered for its involvement in human immunodeficiency virus entry and leukocyte trafficking, is overexpressed in more than 23 human cancers. Zhuang et al. have reported that TMP could downregulate CXCR4 in C6 cells, and further inhibit cell migration, proliferation, and colony formation, and induce $S$ phase arrest more effectively than AMD3100 (a CXCR4 antagonist). The in vivo experiments in rats implanted with $\mathrm{C} 6$ cells showed results analogous to those found in vitro (Yu et al., 2012). In subsequent studies, TMP was found to effectively promote cerebral neurocyte survival by inhibiting hydrogen peroxide $\left(\mathrm{H}_{2} \mathrm{O}_{2}\right)$-induced increase in the intracellular concentration of $\mathrm{Ca}^{2+}$ and glutamate release. Upon using a glioma-neuronal coculturing system, TMP was more effective in these functions compared with AMD3100 (Chen et al., 2013). In 2014, Zhuang et al. studied the presence of high levels of invasion caused by neovascularization of gliomas using a venous endothelial cell line (ECV304) and a rat model. TMP inhibited neovascularization, fibrosis, and thrombosis under pathological conditions, contributing to the downregulation of CXCR4 through the SDF-1/CXCR4 axis (Cai et al., 2014).

There is a relative paucity of research on other tumors of the nervous system. The classic PI3K/AKT pathway remains to be fully investigated, and TMP has been found to affect the downstream functional protein, resulting in a change in tumor biological behavior. In a medulloblastoma cell line (Daoy), TMP inhibited the PI3K/AKT and mTOR signaling pathways by upregulating $\mathrm{miR}-211$ to affect the proliferative, migratory, and invasive abilities of Daoy cells with the increase in the expression of caspase-3, caspase- 9 , and Bax, and a decrease in the expression of Bcl-2, MMP-2, MMP-9, and Vim (Xu et al., 2018). TMP blocked $\mathrm{H}_{2} \mathrm{O}_{2}$-induced apoptosis by regulating the expression of the members of the Bcl-2 family, suppressing cytochrome $c$ release, and activating the caspase cascade in the rat pheochromocytoma-derived cell line PC12 (Cheng et al., 2007).

In contrast to the negative impact on tumor tissue, TMP plays a protective role in brain damage via a mechanism mainly related to the antioxidation or antiapoptotic pathways. In vivo and in vitro experimental studies have shown that TMP can improve cobalt chloride-induced oxidative stress and brain 
TABLE 1 | Clinical application of tetramethylpyrazine (TMP) in cancer therapy.

\begin{tabular}{|c|c|c|c|c|}
\hline $\begin{array}{l}\text { S. } \\
\text { no }\end{array}$ & Research target & Treatment & Research indicator & Effect \\
\hline 1 & $\begin{array}{l}38 \text { patients with lung } \\
\text { cancer }\end{array}$ & $\begin{array}{l}80 \mathrm{mg} \text { of TMP added to } 5 \% \text { GS for intravenous } \\
\text { infusion }\end{array}$ & $\begin{array}{l}\text { Activation, adhesion, gathering and release of platelet; plasma VII C, } \\
\text { VWF, Fg }\end{array}$ & Positive \\
\hline 2 & 56 patients with $\mathrm{NHL}$ & $5 \mathrm{mg} / \mathrm{kg}$ a day intravenous TMP infusions & MDR and overexpression of P-glycoprotein (P-gp) & Positive \\
\hline
\end{tabular}

nerve injury, via a mechanism involving the increased expressions of nuclear factor erythroid 2-related factor 2 (NRF2) and glutamyl cystine ligase to promote the synthesis of glutathione (GSH) and reduce the levels of reactive oxygen species (ROS). Meanwhile, TMP inhibited the expressions of hypoxia-inducible factor $1 \alpha$ (HIF-1a) and nicotinamide adenine dinucleotide phosphate oxidase 2 (NOX2), to inhibit ROS production mediated by HIF-1a and NOX2. Through these two antioxidant pathways, TMP blocks apoptosis, restores mitochondrial function, and protects the brain cells (Guan et al., 2015). TMP may stimulate neuronal differentiation of human neuroblastoma SH-SY5Y cells by enhancing the recruitment of $\mathrm{Ac}-\mathrm{H} 3$ and $\mathrm{Ac}-\mathrm{H} 4$ to the topoisomerase II $\beta$ gene promoter region to regulate neuronal development (Yan et al., 2014). TMP can also activate the mitogen-activated protein kinase (MAPK) signaling pathway by promoting the phosphorylation of extracellular signal-regulated kinase (ERK) $1 / 2$ and reducing the phosphorylation of $\mathrm{P} 38$, thereby promoting brain neural stem cell proliferation and differentiation into neuronal cells under hypoxic conditions (Tian et al., 2010). TMP has a therapeutic effect on neurological diseases. TMP effectively reversed scopolamine-induced memory impairment in rats by improving postsynaptic protein synthesis and restoring the signal conduction of cyclophosphate/protein kinase A/the cAMP response element-binding protein (CREB) pathway ( $\mathrm{Wu}$ et al., 2013). In cultured microglial cells stimulated with A $\beta 25-35$, TMP repressed the inflammatory response in the presence of interferon (IFN)- $\gamma$ and blocked ROS generation and phosphorylation of Akt to alleviate the inflammatory progression of Alzheimer's disease (Kim et al., 2014).

\subsection{Respiratory system}

Lung cancer has the highest incidence and mortality rate worldwide. Among its subtypes, nonsmall cell lung cancer (NSCLC) is the main histological type and accounts for $85 \%$ of all cases. Most patients are already in the middle and late stages of the disease when diagnosed (Herbst et al., 2018). In recent years, precision treatment modalities for lung cancer, such as targeted therapy, antiangiogenic treatment, and immunotherapy, have been rapidly developed. However, the survival period of lung cancer is still unsatisfactory (Hirsch et al., 2017). A study on the lung cancer cell lines A549 and 95D conducted by Huang et al. (2018) showed that TMP decreased cell viability in a dose- and time-dependent manner and suppressed the carcinogenesis of lung cancer cells by arresting the cell cycle at the $S$ phase and inducing mitochondria-dependent apoptosis by regulating caspase- 3 and Bax/Bcl-2. Cyclooxygenase (COX)-2 plays an important role in tumorigenesis and is a critical factor for the invasion and metastasis of lung cancer. Zheng et al. (2012) found that TMP exhibited the same dose- and time-dependent inhibitory effect on the proliferation of the lung cancer cell line A549 by suppressing cell cycle progression, which resulted in the inhibition of invasion in vitro and suppression of metastatic growth in an in vivo metastatic nude mouse model by targeting COX-2.

Hematogenous metastasis is often diagnosed in early-stage lung cancer, particularly, small cell lung cancer. Tumor growth and metastasis of lung cancer depend on the formation of a neovasculature. Antiangiogenic treatment has gradually attracted significant attention (Yi et al., 2019). Research on the pulmonary vascular cell model (microvascular endothelial cell line: HMEC1) showed that TMP could suppress angiogenesis and tumor growth in lung cancer by blocking the BMP/Smad/Id-1 signaling pathway in a dose- and time-dependent manner. In addition, the administration of TMP inhibited the tumor growth of A549 xenografts in nude mice, with reduced expression of CD31, phosphorylated Smad1/5/8, and Id-1 (Jia et al., 2016). Lung cancer patients predominantly express type 2 cytokines. After investigating peripheral blood mononuclear cells obtained from lung cancer patients, Wei et al. $(2002,2004)$ reported that TMP could reverse the predominant type 2 status. This predominant expression of Th2 type cytokines may be related to a lower expression of T-bet or a higher expression of GATA3, with which TMP interferes.

The interaction of platelets in the blood and with TMP can also affect lung cancer progression. TMP, as a blood-activating agent, could increase the adhesion of the lung cancer cell lines PGCL3 and PAa to fibronectin but inhibit the invasion of PGCL3 cells in a Boyden chamber (Zhang et al., 1999). In a comparison of advanced cases of lung carcinoma and matched control subjects, TMP has been shown to have an antimetastatic effect on lung carcinoma as it inhibited the adhesion and aggregatory functions of blood platelets and the activity of coagulation factors (Chen et al., 1997).

\subsection{Urinary system}

Prostate cancer is a common malignant tumor among men, often treated with antiandrogen therapy. Most patients will be nondependent on androgen after 18-24 months of treatment (Cornford et al., 2021).

In prostate cancer cells, TMP treatment reduces viability and increases the rate of apoptosis in a dose-dependent manner. During the expression of long noncoding RNA, DPP10-AS1 is upregulated and becomes associated with CREB-binding protein to induce $\mathrm{H} 3 \mathrm{~K} 27 \mathrm{ac}$ enrichment at the promoter region of the forkhead box M1 (FOXM1) gene (Zhou et al., 2020). Hormone-refractory 


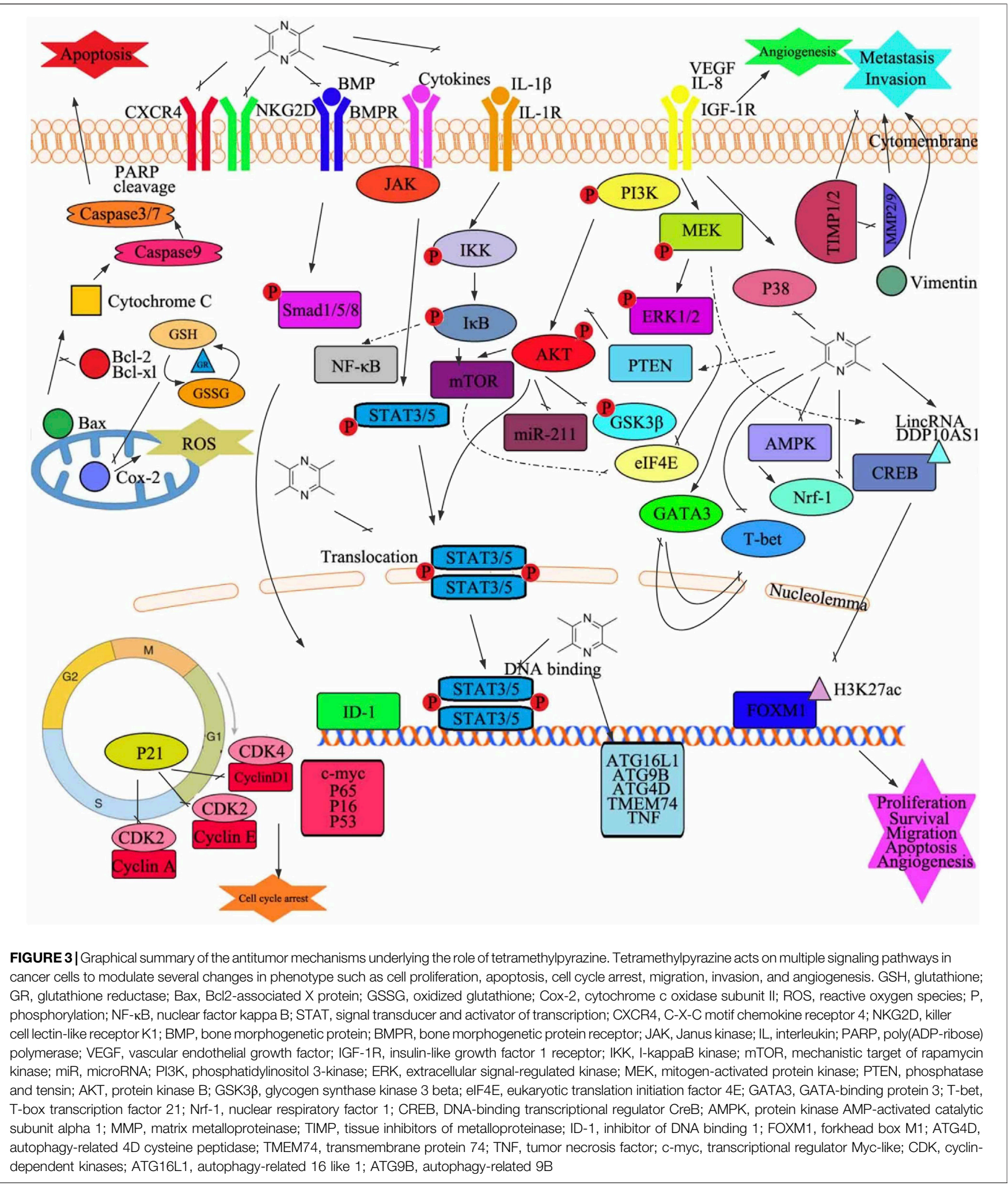

prostate cancer (HRPC) is the final progression stage of prostate cancer and the most difficult to treat. Most patients have concomitant bone metastasis or pelvic lymph node metastasis when the diagnosis is confirmed. Whole-body chemotherapy or palliation is the main treatment modality for HRPC; however, the clinical efficacy is not ideal (Heber et al., 2019). In the HRPC cell line PC-3, TMP reduces cell proliferation and promotes apoptosis by modulating the availability of eIF4E mainly through the mTOR and 
TABLE 2 | Antitumor effect of tetramethylpyrazine against the tumor models of multiple organs.

\begin{tabular}{|c|c|c|c|c|}
\hline S. no & Research target & Molecular target & Mode of action & Reference \\
\hline \multicolumn{5}{|c|}{$\begin{array}{l}\text { Brain and } \\
\text { nervous system }\end{array}$} \\
\hline 1 & $\begin{array}{l}\text { Glioma cell line (C6) and gliomas transplanted } \\
\text { into rat brains }\end{array}$ & $\begin{array}{l}\text { Glutamate-induced increase in } \\
\text { intracellular calcium }\end{array}$ & $\begin{array}{l}\text { Proliferation, neuronal damage, and } \\
\text { migration }\end{array}$ & Fu et al. (2008) \\
\hline 2 & $\begin{array}{l}\text { Glioma cell line (C6) and rats implanted with C6 } \\
\text { cells }\end{array}$ & $\mathrm{CXCR} 4$ & $\begin{array}{l}\text { Migration, proliferation, colony formation, } \\
\text { and S-phase arrest; tumor growth and } \\
\text { microcirculation }\end{array}$ & Yu et al. (2012) \\
\hline 3 & Glioma cell line (C6) and cerebral neurocytes & CXCR4 & Inhibition and neural protection & $\begin{array}{l}\text { Chen et al. } \\
\text { (2013) }\end{array}$ \\
\hline 4 & $\begin{array}{l}\text { Umbilical vein endothelial cell line (ECV304), } \\
\text { corneal neovascularization, and pulmonary } \\
\text { fibrosis in rat model }\end{array}$ & SDF-1/CXCR4 axis & $\begin{array}{l}\text { Neovascularization, fibrosis, and } \\
\text { thrombosis }\end{array}$ & Cai et al. (2014) \\
\hline 5 & Medulloblastoma cell line (Daoy) & $\begin{array}{l}\text { MiR-211, PI3K/AKT, and mTOR } \\
\text { pathways }\end{array}$ & Proliferation, migration, and invasion & Xu et al. (2018) \\
\hline 6 & $\begin{array}{l}\text { Rat pheochromocytoma-derived cell line } \\
\text { (PC12) }\end{array}$ & $\begin{array}{l}\text { Bcl-2, Bax, cytochrome c, and } \\
\text { caspase-3 }\end{array}$ & Apoptosis & $\begin{array}{l}\text { Cheng et al. } \\
(2007)\end{array}$ \\
\hline \multicolumn{5}{|c|}{$\begin{array}{l}\text { Respiratory } \\
\text { system }\end{array}$} \\
\hline 7 & Lung cancer cell line (A549, 95D) & Caspase-3 and Bax/Bcl-2 & $\begin{array}{l}\text { Proliferation, apoptosis, cell cycle arrest (S } \\
\text { phase) }\end{array}$ & $\begin{array}{l}\text { Huang et al. } \\
(2018)\end{array}$ \\
\hline 8 & $\begin{array}{l}\text { Lung cancer cell line (A549) and metastatic } \\
\text { nude mouse model }\end{array}$ & COX-2 and MMP-2/TIMP-2 & $\begin{array}{l}\text { Proliferation, cell cycle arrest, invasion, } \\
\text { and metastasis }\end{array}$ & $\begin{array}{l}\text { Zheng et al. } \\
(2012)\end{array}$ \\
\hline 9 & $\begin{array}{l}\text { Lung cancer cell line (A549), microvascular } \\
\text { endothelial cell line (HMEC-1), A549 xenograft } \\
\text { in nude mice }\end{array}$ & BMP/Smad/ld-1 pathway & $\begin{array}{l}\text { Proliferation, migration, angiogenesis, and } \\
\text { tumor growth }\end{array}$ & Jia et al. (2016) \\
\hline 10 & Lung cancer patients and PBMCs & Th2 type cytokines, T-bet/GATA3 & PBMC & $\begin{array}{l}\text { Wei et al., } 2002 \\
\text { and } 2004\end{array}$ \\
\hline 11 & Lung cancer cell line (PGCL3 and PAa) & No mention & Adhesion and invasion & $\begin{array}{l}\text { Zhang et al. } \\
(1999)\end{array}$ \\
\hline 12 & Advanced cases of lung carcinoma & PAdT, PagT, VIII:C, dWF, and Fg & Metastasis & $\begin{array}{l}\text { Chen et al. } \\
(1997)\end{array}$ \\
\hline \multicolumn{5}{|c|}{ Urinary system } \\
\hline 13 & Prostate cancer cells (PCa cells) & $\begin{array}{l}\text { DPP10-AS1/CBP/FOXM1 signaling } \\
\text { pathway }\end{array}$ & Cell viability and apoptosis & $\begin{array}{l}\text { Zhou et al. } \\
\text { (2020) }\end{array}$ \\
\hline 14 & $\begin{array}{l}\text { Hormone-refractory prostate cancer cell line } \\
\text { (PC-3) }\end{array}$ & $\begin{array}{l}\text { EIF4E, mTOR, and MEK/ERK signaling } \\
\text { pathways }\end{array}$ & Proliferation and apoptosis & $\begin{array}{l}\text { Han et al. } \\
(2015)\end{array}$ \\
\hline 15 & Prostate cancer cell line (PC-3) & FOXM1 & Proliferation, migration, and invasion & $\begin{array}{l}\text { Zhou et al. } \\
\text { (2017) }\end{array}$ \\
\hline 16 & Renal cell carcinoma cell line (ccRCC) & $\begin{array}{l}\text { NKG2D pathway, NKG2DLs, MICA/B, } \\
\text { E-cadherin, vimentin, and fibronectin }\end{array}$ & $\begin{array}{l}\text { Cell viability, proliferation, apoptosis, } \\
\text { invasion, migration, and EMT }\end{array}$ & $\begin{array}{l}\text { Luan et al. } \\
\text { (2016) }\end{array}$ \\
\hline 17 & Bladder carcinoma cells (T24) & $\begin{array}{l}\text { Glutathione metabolism and } \\
\text { glycerophospholipid metabolism }\end{array}$ & $\begin{array}{l}\text { Angiogenesis, proliferation, and } \\
\text { metastasis }\end{array}$ & $\begin{array}{l}\text { Cui et al., } 2019 \\
\text { and } 2020\end{array}$ \\
\hline \multicolumn{5}{|c|}{$\begin{array}{l}\text { Blood and } \\
\text { immune system }\end{array}$} \\
\hline 18 & T-cell leukemia cell line (SKW-3) & ICAM-1 and LFA-1 & Adhesion & $\begin{array}{l}\text { Zhao et al. } \\
\text { (2000) }\end{array}$ \\
\hline 19 & Leukemia cell line (HL-60) & C-myc, p27, CDK2, and cyclinE1 & $\begin{array}{l}\text { Differentiation, proliferation, and cell cycle } \\
\text { arrest }\end{array}$ & Wu et al. (2011) \\
\hline 20 & $\begin{array}{l}\text { Acute lymphoblastic leukemia cell line (Jurkat } \\
\text { and SUP-B15) }\end{array}$ & GSK-3 $\beta, N F-\kappa B$, and c-myc & $\begin{array}{l}\text { Proliferation, apoptosis, and cell cycle } \\
\text { arrest }\end{array}$ & $\begin{array}{l}\text { Wang et al. } \\
(2015)\end{array}$ \\
\hline 21 & Leukemia cell line (U937) & Bcl-2, caspase-3 & $\begin{array}{l}\text { Proliferation, apoptosis, and cell cycle } \\
\text { arrest }\end{array}$ & $\begin{array}{l}\text { Wang et al. } \\
(2015)\end{array}$ \\
\hline 22 & Non-Hodgkin's lymphoma (NHL) patients & P-glycoprotein (P-gp) & MDR & $\begin{array}{l}\text { Yang and } \\
\text { Jiang, (2010) }\end{array}$ \\
\hline \multicolumn{5}{|c|}{ Digestive system } \\
\hline 23 & Rats with DEN-induced HCC & $\begin{array}{l}\text { Mitochondrial apoptotic pathway; Akt } \\
\text { and ERK pathway }\end{array}$ & $\begin{array}{l}\text { Tumor growth, apoptosis, and cell cycle } \\
\text { arrest(G2/M) }\end{array}$ & $\begin{array}{l}\text { Cao et al. } \\
(2015)\end{array}$ \\
\hline 24 & Mice with hepatic precancerous lesions & $\begin{array}{l}\text { Serum marker enzymes, bile canaliculi } \\
\text { hyperplasia }\end{array}$ & $\begin{array}{l}\text { Pharmacokinetic variation and } \\
\text { hepatoprotective effects }\end{array}$ & $\begin{array}{l}\text { Feng et al. } \\
(2014)\end{array}$ \\
\hline 25 & HCC cell line (HepG2) & $\begin{array}{l}\text { P53, Bcl-2/Bax protein ratio, } \\
\text { cytochrome c, and caspase }\end{array}$ & $\begin{array}{l}\text { Proliferation, mitochondrial apoptosis, cell } \\
\text { cycle arrest (G0/G1 phase) }\end{array}$ & Bi et al. (2016) \\
\hline 26 & $\begin{array}{l}\text { HCC cell line (HepG2) and xenograft tumor } \\
\text { models }\end{array}$ & Caspase-3 and PARP & $\begin{array}{l}\text { Proliferation, autophagy, apoptosis, } \\
\text { and ROS }\end{array}$ & $\begin{array}{l}\text { Cao et al. } \\
(2015)\end{array}$ \\
\hline
\end{tabular}


TABLE 2 | (Continued) Antitumor effect of tetramethylpyrazine against the tumor models of multiple organs.

\begin{tabular}{|c|c|c|c|c|}
\hline S. no & Research target & Molecular target & Mode of action & Reference \\
\hline 27 & HCC cell line (HepG2) & $\begin{array}{l}\mathrm{IL}-1 \mathrm{R} 1 / \mathrm{|} \mathrm{\kappa} / \mathrm{IKK} / \mathrm{NF}-\kappa \mathrm{B} \text { signaling } \\
\text { pathway }\end{array}$ & Invasion and migration & $\begin{array}{l}\text { Wang et al. } \\
(2020)\end{array}$ \\
\hline 28 & HCC cell line (HepG2) & GSH/GSSG & $\begin{array}{l}\text { Intracellular glutathione balance } \\
\text { disruption and cytotoxicity }\end{array}$ & $\begin{array}{l}\text { Ishida et al. } \\
(2012)\end{array}$ \\
\hline 29 & Gastric cancer cell line (SGC7901) & $\begin{array}{l}\text { ROS, AMPK, cytochrome c, caspase- } \\
\text { 9, caspase- } 3 \text {, and mitochondrial } \\
\text { membrane potential }\end{array}$ & Apoptosis & Yi et al. (2013) \\
\hline 30 & Gastric cancer cell line (SGC-7901) & NF-xBp65, cyclinD1, and p16 & Proliferation and apoptosis & Ji et al. (2014) \\
\hline 31 & Colorectal cancer cell lines (SW480 and CT26) & $\begin{array}{l}\text { P53-dependent mitochondrial } \\
\text { pathway }\end{array}$ & Apoptosis, cell cycle arrest (G0/G1) & $\begin{array}{l}\text { Bian et al. } \\
(2021)\end{array}$ \\
\hline 32 & $\begin{array}{l}\text { Colorectal cancer cell line }(\mathrm{HCT}-116) \text { and } \\
\text { tumor-bearing mice }\end{array}$ & $\begin{array}{l}\text { EMT(TGF- } \beta 1) \text { and Wnt } / \beta \text {-catenin } \\
\text { pathway }(p-A k t, p-G S K-3 \beta)\end{array}$ & $\begin{array}{l}\text { ROS, proliferation, migration, invasion, } \\
\text { heteroadhesion, EMT, tumor growth, and } \\
\text { lung metastasis in vivo }\end{array}$ & $\begin{array}{l}\text { Zou et al. } \\
(2018)\end{array}$ \\
\hline \multicolumn{5}{|c|}{$\begin{array}{l}\text { Reproductive } \\
\text { system }\end{array}$} \\
\hline 33 & $\begin{array}{l}\text { Breast cancer cell line (MDA-MB-231) and } \\
\text { xenograft tumors in nude mice }\end{array}$ & No mention & $\begin{array}{l}\text { Proliferation, apoptosis, and cell cycle } \\
\text { arrest (G0/G1) }\end{array}$ & $\begin{array}{l}\text { Pan et al. } \\
(2015)\end{array}$ \\
\hline 34 & Breast cancer cell line (MDA-MB-231) & Akt and caspase-3 & $\begin{array}{l}\text { Proliferation, apoptosis, migration, and } \\
\text { invasion }\end{array}$ & $\begin{array}{l}\text { Shen et al. } \\
(2018)\end{array}$ \\
\hline 35 & $\begin{array}{l}\text { Human breast cancer cell lines (MCF-7, MDA- } \\
\text { MB-231), murine mammary carcinoma cell line } \\
\text { (4T1), and 4T1 tumor-bearing mouse model }\end{array}$ & STAT3 & Proliferation, migration, and tumor growth & $\begin{array}{l}\text { Fan et al. } \\
(2021)\end{array}$ \\
\hline 36 & $\begin{array}{l}\text { Triple-negative breast cancer cell line (MDA- } \\
\text { MB-231) }\end{array}$ & Heparanase & Angiogenesis and autophagy & Li et al. (2021) \\
\hline 37 & $\begin{array}{l}\text { Ovarian cancer (OC) cell line (SK-OV-3 and } \\
\text { OVCAR-3) }\end{array}$ & MiR-211 & Proliferation, migration, and invasion & $\begin{array}{l}\text { Zhang et al. } \\
(2021)\end{array}$ \\
\hline 38 & Ovarian carcinoma cell line (SKOV3) & $\begin{array}{l}\text { IL-8 and ERK1/2, p38, and AP-1 } \\
\text { pathways }\end{array}$ & Invasion and migration & Yin et al. (2011) \\
\hline \multicolumn{5}{|c|}{ Other organs } \\
\hline 39 & $\begin{array}{l}\text { Melanoma cell line (B16F10) spontaneous } \\
\text { metastasis model }\end{array}$ & CD34 and VEGF & Angiogenesis and metastasis & $\begin{array}{l}\text { Chen et al. } \\
\text { (2009) }\end{array}$ \\
\hline 40 & $\begin{array}{l}\text { UVA-induced melanoma/keratinocyte } \\
\text { coculture system }\end{array}$ & $\begin{array}{l}\text { TRP1, MITF, MAPK, TNF } \alpha, I L-1 \beta, I L-8 \text {, } \\
\text { and GM-CSF }\end{array}$ & $\begin{array}{l}\text { Melanin content, cell viability, and } \\
\text { cytokines release }\end{array}$ & $\begin{array}{l}\text { Yeom et al. } \\
(2014)\end{array}$ \\
\hline 41 & $\begin{array}{l}\text { Retinoblastoma cell line (WERI-Rb1), WERI- } \\
\text { Rb1 cells injected into the eyes of athymic } \\
\text { nude mice }\end{array}$ & Nrf- 1 and CXCR4 & $\begin{array}{l}\text { Proliferation, cell cycle arrest(G1-phase), } \\
\text { and tumor growth }\end{array}$ & $\begin{array}{l}\text { Wu et al., } 2017 \\
\text { and } 2019\end{array}$ \\
\hline 42 & $\begin{array}{l}\text { Osteosarcoma cell line (MG-63, SAOS-2, and } \\
\text { U2OS), xenograft tumor mouse model }\end{array}$ & NF-кB, p65, BCL-2, and cyclin D1 & $\begin{array}{l}\text { Proliferation, apoptosis, cell cycle arrest } \\
\text { (G0/G1), tumor growth }\end{array}$ & $\begin{array}{l}\text { Wang et al. } \\
(2013)\end{array}$ \\
\hline 43 & $\begin{array}{l}\text { Pharyngeal squamous cell line (FADU), HeLa, } \\
\text { Hep G2, MCF-7, and A549 }\end{array}$ & $\begin{array}{l}\text { Depolarization of mitochondrial } \\
\text { membrane potential }\end{array}$ & $\begin{array}{l}\text { Proliferation, apoptosis, cell cycle arrest (S } \\
\text { phase) }\end{array}$ & $\begin{array}{l}\text { Wang et al. } \\
(2019)\end{array}$ \\
\hline \multicolumn{5}{|c|}{ Adriamycin } \\
\hline 44 & HCC cell line (HepG2/ADM) & P-gp170 and MDR1 & MDR & $\begin{array}{l}\text { Mei et al. } \\
(2004)\end{array}$ \\
\hline 45 & HCC cell line (BEL-7402/ADM) & $\begin{array}{l}\text { P-glycoprotein, MDR1, MRP2, MRP3, } \\
\text { and MRP5 }\end{array}$ & MDR & $\begin{array}{l}\text { Wang et al. } \\
(2010)\end{array}$ \\
\hline 46 & Breast cancer cell line (MCF-7/ADR) & No mention & MDR & $\begin{array}{l}\text { Zhou et al. } \\
(2007)\end{array}$ \\
\hline 47 & Breast cancer cell line (MCF-7/dox) & P-glycoprotein (P-gp) & MDR & $\begin{array}{l}\text { Zhang et al. } \\
\text { (2012) }\end{array}$ \\
\hline 48 & $\begin{array}{l}\text { Breast cancer cell line (MCF-7/A) and tumor } \\
\text { xenografts in vivo }\end{array}$ & GSH, GST $\pi$, and JNK & Proliferation, ADR resistance, MDR & $\begin{array}{l}\text { Zhang et al. } \\
\text { (2014) }\end{array}$ \\
\hline 49 & Breast cancer cell line (MCF-7/A) & EGFR/PI3K/Akt pathway & ADR resistance, apoptosis & $\begin{array}{l}\text { Chen et al. } \\
\text { (2014) }\end{array}$ \\
\hline 50 & $\begin{array}{l}\text { Human myelogenous leukemia cell line } \\
\text { (K562/A02) }\end{array}$ & GST $\pi$ & MDR & $\begin{array}{l}\text { Song et al. } \\
\text { (2011) }\end{array}$ \\
\hline 51 & $\begin{array}{l}\text { Breast cancer tissue samples and breast } \\
\text { cancer cell lines (MCF-7 and T47D) }\end{array}$ & JAK2/STAT3 pathway & Epirubicin resistance & Liu et al. (2020) \\
\hline \multicolumn{5}{|c|}{ Cisplatin } \\
\hline 52 & $\begin{array}{l}\text { Lewis lung cancer mice (nonsmall cell lung } \\
\text { cancer) }\end{array}$ & VEGF, KLF4, and ADAMTS1 & Tumor growth and angiogenesis & $\begin{array}{l}\text { Tang et al. } \\
(2017)\end{array}$ \\
\hline 53 & $\begin{array}{l}\text { Lung cancer cell line (A549, SPC-A-1, and } \\
\text { LTEP-G-2) and implanted human lung cancer } \\
\text { in mice }\end{array}$ & $\begin{array}{l}\text { TrxR/Trx system, NF-kB, AKT, and } \\
\text { ERK signaling pathways }\end{array}$ & MDR, ROS, apoptosis, tumor growth & Ai et al. (2016) \\
\hline
\end{tabular}

(Continued on following page) 
TABLE 2 | (Continued) Antitumor effect of tetramethylpyrazine against the tumor models of multiple organs.

\begin{tabular}{|c|c|c|c|c|}
\hline S. no & Research target & Molecular target & Mode of action & Reference \\
\hline 54 & $\begin{array}{l}\text { Bladder cancer cell line (Pumc-91/ADM and } \\
\text { T24/DDP) }\end{array}$ & MRP1, GST, BCL-2, and TOPO-II & MDR and cell cycle arrest & $\begin{array}{l}\text { Wang et al. } \\
(2016)\end{array}$ \\
\hline \multicolumn{5}{|c|}{ Paclitaxel } \\
\hline 55 & Lung cancer cell line (A549) & VEGF, MMP2, TGF- $\beta 1$, and E-cadherin & Metastasis & Xie et al. (2019) \\
\hline 56 & $\begin{array}{l}\text { Ovarian cancer cell line (A2780 and SKOV3) } \\
\text { and A2780-heterografted BALB/c nude mice }\end{array}$ & ERK1/2 and Akt pathways & $\begin{array}{l}\text { Angiogenesis, apoptosis, proliferation, } \\
\text { and migration }\end{array}$ & $\begin{array}{l}\text { Zou et al. } \\
(2019)\end{array}$ \\
\hline \multicolumn{5}{|c|}{ 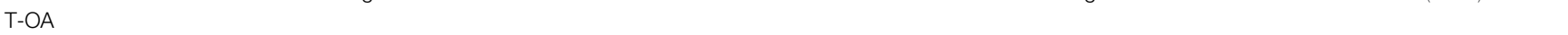 } \\
\hline 57 & S180 mice (sarcoma) & $\mathrm{NF}-\mathrm{kB} / \mathrm{p} 65$ and $\mathrm{COX}-2$ & $\begin{array}{l}\text { Pharmacokinetic evaluation and } \\
\text { antitumor activity }\end{array}$ & $\begin{array}{l}\text { Wang et al. } \\
(2013)\end{array}$ \\
\hline 58 & HCC cell line (Bel-7402) & NF-kB/p65 and COX-2 & Apoptosis & $\begin{array}{l}\text { Zhang et al. } \\
(2015)\end{array}$ \\
\hline 59 & $\begin{array}{l}\text { HCC cell line (HepG2) and HT-29, HeLa, and } \\
\text { BGC-823 }\end{array}$ & No mention & $\begin{array}{l}\text { Cytotoxicity, apoptosis, and } \\
\text { nephrotoxicity }\end{array}$ & $\begin{array}{l}\text { Chu et al. } \\
(2014)\end{array}$ \\
\hline \multicolumn{5}{|c|}{ DT-010 } \\
\hline 60 & Breast cell line (MCF-7) & GRP78 & Dox-induced toxicity, apoptosis & $\begin{array}{l}\text { Wang et al. } \\
(2016)\end{array}$ \\
\hline 61 & Breast cancer cell line (MCF-7/ADR) & $\begin{array}{l}\text { P53, P-glycoprotein, and mitochondrial } \\
\text { complex II }\end{array}$ & $\begin{array}{l}\text { Proliferation, apoptosis, glycolysis, } \\
\text { mitochondrial function, and metabolic } \\
\text { process }\end{array}$ & $\begin{array}{l}\text { Zhou et al. } \\
\text { (2019) }\end{array}$ \\
\hline 62 & $\begin{array}{l}\text { Breast cancer cell line (MCF-7 and MDA- } \\
\text { MB-231) }\end{array}$ & Mitochondrial complex II & $\begin{array}{l}\text { Proliferation, cell cycle arrest, ROS } \\
\text { generation, and mitochondrial } \\
\text { dysfunction }\end{array}$ & $\begin{array}{l}\text { Wang et al. } \\
\text { (2016) }\end{array}$ \\
\hline \multicolumn{5}{|c|}{ CSTMP } \\
\hline 63 & Lung cancer cell line (A549) & $\begin{array}{l}\text { IRE1 } 1 \text {-TRAF2-ASK1 complex, ER } \\
\text { stress, and JNK activation }\end{array}$ & $\begin{array}{l}\text { Proliferation, cell cycle arrest, } \\
\text { mitochondria-dependent apoptosis }\end{array}$ & $\begin{array}{l}\text { Zhang et al. } \\
\text { (2016) }\end{array}$ \\
\hline 64 & Myeloma cell line (RPMI8226) & $\begin{array}{l}\text { CHOP, GRP78, GRP94, cleaved } \\
\text { caspase-12, PERK-elF2 } \alpha \text {, IRE1 } \alpha \text {, and } \\
\text { ATF6 }\end{array}$ & $\begin{array}{l}\text { Apoptosis, ER stress, and mitochondrial } \\
\text { dysfunction }\end{array}$ & $\begin{array}{l}\text { Sun et al. } \\
(2016)\end{array}$ \\
\hline
\end{tabular}

MEK/ERK signaling pathways to inhibit cap-dependent translation (Han et al., 2015). In addition, Zhou et al. (2017) reported that TMP inhibited PC-3 cell proliferation, migration, and invasion by downregulating FOXM1 through treatment with TMP and a pcDNA-FOXM1 plasmid.

Clear cell renal cell carcinoma (ccRCC) is the commonest type of kidney cancer. The associated mortality rate is as high as $47 \%$, making it a significant threat to patients (Jonasch et al., 2021). The antitumor efficacy of TMP was investigated in the human ccRCC cell line and found to inhibit ccRCC cell viability, proliferation, apoptosis, invasion, and migration by inhibiting the NKG2D-related signaling pathway to further suppress epithelial-mesenchymal transition (EMT) progression. The binding of NKG2D to its ligands activates natural killer (NK) cells to increase NK cell-mediated cytotoxicity against cancer cells with a high expression of major histocompatibility complex class I chain-related molecules A and B (Luan et al., 2016). BA-12, a TMP-betulinic acid derivative, exhibits potent antitumor activities by blocking angiogenesis to inhibit the growth and metastasis of bladder carcinoma cells (T24); this involves interfering with GSH metabolism and activating glycerophospholipid metabolism (Cui et al., 2019; Cui et al., 2020).

TMP plays a renoprotective role by protecting kidney tissues and cells against apoptosis, has an antioxidant function to ameliorate kidney injury and kidney tissue fibrosis. Yang et al. (2011) found that TMP can improve the pathological conditions of rats with diabetic nephropathy induced by streptozocin by decreasing the expression of vascular endothelial growth factor (VEGF). Another study reported that TMP plays a protective role against kidney injury among rats. Its mechanism may involve the inhibition of the P38 MAPK expression and the transcriptional factor forkhead box $\mathrm{O} 1$ which blocks the signal transduction pathway mediated by these two proteins, thus playing an antiapoptotic role. In addition, TMP plays a protective role against human renal proximal tubule injury induced by sodium arsenate, via a mechanism involving the inhibition of ROS production, increasing the level of GSH, and increasing cytochrome $\mathrm{C}$ oxidase activity to improve mitochondrial dysfunction (Gong et al., 2015). TMP also induces tubulointerstitial fibrosis and resists ureteric obstruction via multiple pathways. Possible mechanisms involved in this change include the transdifferentiation of renal tubular mesenchymal cells and exerting antioxidant effects. This process downregulates the expression of TGF43L protein and connective tissue growth factor, and upregulates hepatocyte growth factor and BMP-7 (Yuan et al., 2012).

\subsection{Blood and immune system}

Acute leukemia is the commonest malignant tumor among children and adolescents, mainly treated with chemotherapy. Treatment failure and recurrence caused by reduced chemotherapy sensitivity and drug resistance are major challenges faced during leukemia treatment (Cartel et al., 2021). Lymphocyte function-associated antigen-1 (LFA-1) is expressed on the surfaces of the T-cell leukemia cell line 
SKW-3. Red blood cells coupled with intercellular adhesion molecule-1 (ICAM-1) are carriers for LFA-1 and ICAM-1, which mediate the adhesion properties of cells (Zhao et al., 2000). Small doses of TMP induce the nonterminal differentiation and proliferation of the leukemia cell line HL60 in a dose- and time-dependent manner, in addition to synergistically blocking the cell cycle progression of HL-60 cells in the G0/G1 phase (Wu et al., 2011). In acute lymphoblastic leukemia cell lines Jurkat and SUP-B15, TMP induces apoptosis and causes cell cycle arrest at the G0/G1 phase by downregulating GSK-3 $\beta$, which further prevents the induced translocation of NF- $\mathrm{kB}$ and c-myc from the cytoplasm to the nucleus (Wang et al., 2015). In the leukemia cell line U937, TMP inhibits cellular proliferation and induces apoptosis, via a mechanism possibly associated with its impact on the cell cycle distribution, regulation of Bcl-2 expression, and finally via caspase-3 activation (Wang et al., 2015).

Research has shown that TMP also plays an effective role in the treatment of lymphoma. Among 60 patients, TMP was found to act as a salvage agent in combination with chemotherapy and could increase the response rate, prolong the progression-free survival with manageable toxicity, and correlate with p-glycoprotein (P-gp) expression in relapsed or refractory non-Hodgkin's lymphoma (NHL) (Yang et al., 2010).

\subsection{Digestive system}

Hepatocellular carcinoma (HCC) is one of the most common malignant tumors. The latest data show that the incidence of HCC is the sixth highest, with the third highest mortality rate (Yeung et al., 2022) among all malignant tumors. More than $80 \%$ of the HCC patients are already in an advanced stage at diagnosis or lose the opportunity for surgery. Even among patients who have undergone radical surgery, the 2-year recurrence rate remains at up to 50\% (Shiffman, 2018). This high recurrence rate may be related to the resistance to single-agent chemotherapy or combined chemotherapy (Perboni et al., 2010). TMP could significantly inhibit tumor development in rats with diethylnitrosamine-induced HCC by inducing apoptosis and cell cycle arrest at the G2/M phase through the mitochondrial apoptotic pathway (Cao et al., 2015). Upon detecting pharmacokinetic variations of TMP phosphate after oral administration in mice with hepatic precancerous lesions, TMP was partly effective in protecting the liver from carcinogenesis initiated by diethylnitrosamine; hepatic insufficiency could alter its pharmacokinetics (Feng et al., 2014).

TMP significantly inhibited HCC cell line (HepG2) proliferation, and induced cell cycle arrest at the G0/G1 checkpoint and caspase-dependent mitochondrial apoptosis in vitro (Bi et al., 2016). TMP induced ROS generation and the inhibition of ROS reduced the antitumor function to regulate autophagy and proliferation by cleaving caspase- 3 and PARP in HepG2 cells and xenograft tumor models (Cao et al., 2015). As a major active component of TOGA, a novel conjugate, TMP could prevent the invasion and migration of HepG2 cells induced by tumor-associated macrophages or IL- $1 \beta$ through the IL-1R1/IkB/ IKK/NF- $\kappa \mathrm{B}$ signaling pathway with the decreased expression of the EMT-related proteins Snail and Vimentin (Wang et al., 2020).
As a model compound, 3-hydro-2,2,5,6-TMP (DHP-3) exerted cytotoxic activity by disrupting the intracellular GSH balance in HepG2 cells in a concentration range of $10 \mu \mathrm{M}-1 \mathrm{mM}$ and significantly so at the highest concentration (Ishida et al., 2012). TMP could alleviate the hepatotoxicity resulting from cyclophosphamide treatment as evidenced by improvement in the structure and function of the liver, and inhibition of oxidative stress and inflammation with accompanying pyroptosis, which was positively correlated with the inhibition of the Txnip/Trx/

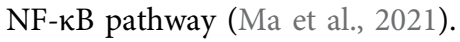

TMP also has an inhibitory effect against gastrointestinal tumors. The induction of apoptosis by TMP in the gastric carcinoma cell line SGC7901 is associated with the activation of the ROS/AMPK (AMP-activated protein kinase) pathway, and AMPK activation induces apoptosis through the mitochondrial apoptotic pathway (Yi et al., 2013). TMP also exhibits significant antiproliferative and proapoptotic properties, regulated by NF$\kappa \mathrm{B}, \mathrm{p} 65$, cyclinD1, and p16 in SGC-7901 cells (Ji et al., 2014). TMP could induce colorectal cancer cell line (SW480 and CT26) apoptosis via a $\mathrm{p} 53$-dependent mitochondrial pathway and cell cycle arrest at the G0/G1 phase; TMP-induced apoptosis and cell cycle arrest were markedly reversed by pifithrin-a (a p53 inhibitor) (Bian et al., 2021). TMP possesses a water-soluble pyrazine skeleton and can inhibit the proliferation and metastasis of cancer cells. Zou et al. (2018) synthesized a compound by replacing the trimethoxyphenyl group of piperlongumine 1 with a TMP moiety. In the colorectal cancer cell line HCT-116, this compound increased ROS levels, and inhibited proliferation, migration, invasion, and heteroadhesion to a greater extent than piperlongumine 1 through EMT induced by TGF- $\beta 1$ and Wnt/ $\beta$-catenin activation by inhibiting Akt and GSK-3 $\beta$ phosphorylation, in addition to suppressing tumor growth and lung metastasis in vivo to prolong the survival of tumor-bearing mice (Zou et al., 2018).

\subsection{Reproductive system}

Breast cancer is one of the most common malignant tumors worldwide and its associated mortality rate is the second highest among all malignant tumors (Siegel et al., 2020).

Based on the expression of estrogen receptor (ER), progesterone receptor (PR), human epidermal growth factor receptor-2 (HER2), and Ki-67, breast cancer can be divided into the following types: the luminal (luminal or hormone receptor positive) $\mathrm{A}$, luminal $\mathrm{B}$, Her-2 overexpression, and basal-like (substrate) types (Viale et al., 2019). The molecular profiles of breast cancer are closely related to their pathological features and clinical prognosis (Tran and Bedard, 2011). Endocrine treatments, such as tamoxifen administration and chemotherapy often cause drug resistance, which leads to a relatively poor prognosis (Viedma-Rodríguez et al., 2014). In the breast cancer cell line MDA-MB-231, TMP inhibited cell survival, and induced apoptosis and cell cycle arrest at the G0/G1 phase. The in vivo findings among xenograft tumors established in nude mice were consistent with those found in vitro (Pan et al., 2015). TMP significantly inhibited the viability, migration, and invasion rates, and increased the apoptosis of cells in a dosedependent manner, as in MDA-MB-231 cells, by inhibiting the 
activity of Akt and increasing the activity of caspase-3 (Shen et al., 2018). Signal transducer and activator of transcription 3 (STAT3) is overexpressed and hyperactivated in tumors. Statmp-151, a TMP derivative, could also act as a novel small molecule Stat3 inhibitor against breast cancer by influencing the mitochondrial membrane potential and ROS generation (Fan et al., 2021).

ER/PR-positive patients account for approximately $70 \%$ of all breast cancer patients; triple-negative breast cancer accounts for $19 \%$, and the Her-2 overexpression type accounts for the remainder (Viale et al., 2019). ER positivity is often considered a good prognostic factor. Due to the lack of corresponding treatment targets, triple-negative breast cancer is considered to have the worst prognosis among patients with breast cancer. TMP, as a component of SANT, a novel Chinese herbal monomer combination, decreased tumor growth and angiogenesis in vivo and in vitro by modulating autophagy in heparinaseoverexpressed triple-negative breast cancer. During this process, the expression levels of the ATG16L1, ATG9B, and $A T G 4 D$ genes increased and those of the TMEM74 and TNF genes decreased. Additionally, the protein levels of HB-EGF, thrombospondin-2, amphiregulin, leptin, IGFBP-9, EGF, coagulation factor III, and MMP-9 (pro and active forms) in the tumor decreased, whereas those of serpin E1 and platelet factor 4 increased (Li et al., 2021).

Chemotherapy is an important strategy for treating breast cancer; however, the occurrence of drug resistance during chemotherapy often leads to failure of breast cancer treatment (Holohan et al., 2013). Drug resistance has become one of the main obstacles to breast cancer treatment. Consensus regarding the use of TMP to relieve tumor resistance has been reached.

Due to a lack of an effective early detection method, typical clinical symptoms are the most important reasons for delaying ovarian cancer diagnosis. Approximately $70 \%$ of the patients with ovarian cancer are diagnosed at an advanced stage (Snijders et al., 2017). The high mortality rate of ovarian cancer is attributed to the characteristics of its distant metastasis (Li et al., 2005). TMP can reduce the viability, proliferation, migration, and invasion ability of the human ovarian carcinoma cell lines SK-OV-3 and OVCAR- 3 by regulating miR-211, and the EMT is also involved in this process (Zhang et al., 2021). TMP also inhibits the invasion and migration of SK-OV-3 cells by decreasing the expression of IL-8 through the ERK1/2, p38, and AP-1 signaling pathways, and IL-8 expression was significantly inhibited after coincubation with PD98059 (an ERK inhibitor) and SB203580 (a p38 inhibitor) (Yin et al., 2011).

\subsection{Other organs}

Malignant melanoma has a high invasiveness and is associated with a high mortality rate. Early-stage melanoma can be surgically resected, and the 5-year survival rate can reach $95 \%$. However, advanced, or unresectable melanoma constitutes a major challenge in the treatment of melanoma (Ubellacker et al., 2020). In the melanoma cell line B16F10 spontaneous metastasis model, TMP inhibited tumor metastasis through its antiangiogenic activity by decreasing the expression of $\mathrm{CD} 34$ and VEGF in the primary tumor tissue and reducing the number of metastase nodi on the lung surface (Chen et al., 2009). TMP was also studied in an ultraviolet A-induced melanoma/keratinocyte coculture system, in which it regulates melanogenesis by enhancing inflammation and decreasing the levels of melanogenic factors (TRP1, MITF, and MAPK) (Yeom et al., 2014).

Retinoblastoma is the most common ocular tumor among children and causes extensive damage. Wu et al. (2017) reported interesting findings on the treatment of retinoblastoma with TMP. In the retinoblastoma cell line WERI-Rb1, TMP significantly downregulated the expression of CXCR4 in a time-dependent manner by reducing the expression of the transcription factor nuclear respiratory factor-1 (Nrf-1). Moreover, it inhibited cell proliferation as an effective CXCR4 antagonist (such as AMD3100) and induced G1-phase arrest in cells seeded at high-density. In addition, TMP protected normal retinal neurocytes from $\mathrm{H}_{2} \mathrm{O}_{2}$-induced damage by downregulating CXCR4 (Wu et al., 2017; Wu et al., 2019).

In osteosarcoma cell lines (MG-63, SAOS-2, and U2OS), TMP inhibited cell proliferation and induced apoptosis and G0/G1 arrest in a dose-dependent manner by upregulating the expressions of cytosolic NF- $\mathrm{kB}$ and p65, while downregulating the nuclear expressions of NF- $\mathrm{kB}, \mathrm{p} 65, \mathrm{Bcl}-2$, and cyclin D1. In addition, TMP exerted an antitumor effect against osteosarcoma in a xenograft tumor mouse model and exhibited a low level of toxicity (Wang et al., 2013). Wang et al. (2019). Synthesized TMP dimers and seven TMP tetramers were linked by alkane diamine, most of which showed better cytotoxicity than the TMP monomer. The TMP dimer $8 \mathrm{e}$ linked with decane-1,10diamine exhibited the highest cytotoxicity in the pharyngeal squamous carcinoma cell line FADU and induced the apoptosis of $\mathrm{FaDu}$ cells by depolarizing the mitochondrial membrane potential and $\mathrm{S}$ phase cell cycle arrest.

\section{EFFECTS AND REVERSE FUNCTION OF MULTIDRUG RESISTANCE TO CHEMOTHERAPEUTIC AGENTS}

Tumor multidrug resistance (MDR) is a major obstacle to cancer chemotherapy. MDR involves the imbalance of multiple mechanisms, including the decrease in concentration of intracellular drugs, changes in drug target molecules, metabolic detoxification, and DNA damage repair function (Tinoush et al., 2020). The need to overcome MDR in tumor cells and improve the efficacy of antitumor drugs remains a key challenge that must be addressed. Recent studies suggest that TMP may reverse tumor MDR, although the mechanism for this remains elusive.

Chemotherapy significantly impacts the physique of the patient, which reduces their tolerance of chemotherapy and overall quality of life. Therefore, it is necessary to continue to explore new treatment options to allow patients undergoing chemotherapy to obtain more benefits. TMP treatment of patients with advanced tumors can reduce toxicity and enhance the efficacy of chemotherapy. For patients with poor general conditions and a strong willingness to use traditional Chinese medicine, a combination of traditional Chinese medicine 
and chemotherapy may be an option. The amphiphilic paclitaxelss-TMP conjugate that readily self-assembles into stable nanoparticles in aqueous solution belongs to a redoxresponsive carrier-free nanosystem with intrinsic amphiphilicity, which exhibits higher cytotoxicity by being associated with a greater apoptosis rate and cell cycle arrest than monotherapy or combination therapy with free drugs. In addition, this treatment also shows tumor-specific accumulation and excellent antitumor activity in A2780 xenograft mice (Zou et al., 2021).

\subsection{Adriamycin}

Adriamycin, also known as doxorubicin, is an antitumor antibiotic that inhibits the synthesis of RNA and DNA. This drug nonspecifically targets the cell cycle and has a damaging effect on tumor cells in various phases of the growth cycle. Therefore, it exhibits a wide range of biochemical effects on the body and has a strong cytotoxic effect (Li et al., 2021; Riaz and Hussain, 2021). The effectiveness of Adriamycin in the treatment of cancer has been limited by the development of drug resistance. TMP showed a potentiating effect on the cytotoxicity of Adriamycin in vitro and partly reversed adriamycin resistance in the resistant mouse cell line EAC (Hu et al., 1993). TMP can reverse MDR of the HCC cell line HepG2/ADM by enhancing the density of adriamycin in the cell and increasing its cytotoxicity. In this process, the transcriptional activity of MDR1 and the expression of P-gp170 decreases (Mei et al., 2004). TMP also reverses MDR in the HCC cell line BEL-7402/ADM (Wang et al., 2010). Zhou (2007) showed that the average initial adriamycin efflux rate in the breast cancer cell line MCF-7/ ADR was higher than that in MCF-7. After treatment with TMP, the drug efflux rate of the MCF-7/ADR cells was reduced to approximately half of that in cells without inhibitors. In the breast cancer cell line MCF-7/Dox, TMP increased the intracellular concentration of adriamycin and inhibited the P-gp-mediated efflux of doxorubicin in a dose-dependent manner, which was induced by inhibiting the ATPase activity of P-gp (Zhang et al., 2012). DLJ14, a TMP piperazine derivative, could serve as a promising chemosensitization candidate for the reversal of $M D R$ in the breast cancer cell line (MCF-7/A). It increases the intracellular accumulation of adriamycin by inhibiting the GSH level and the GSH peroxidase and GSH S-transferase (GST) activity (Zhang et al., 2014). Combination treatment with DLJ14 and adriamycin could inhibit the growth of adriamycin-resistant MCF-7/A cells by inhibiting the EGFR/ PI3K/Akt survival pathway and inducing apoptosis via the mitochondrial-apoptosis pathway (Chen et al., 2014). Overexpression of GST $\pi$ is one of the mechanisms that contributes to MDR. DLJ14 may trigger the reversal of MDR in adriamycin-resistant human myelogenous leukemia (K562/A02) cells by modulating the expression of GST $\pi$ and GST-related enzymes (Song et al., 2011). The cardiotoxicity and endotheliotoxicity of adriamycin limit its clinical application in cancer treatment. TMP protects the vascular endothelium against adriamycin-induced injury by upregulating 14-3-3 $\gamma$ expression, promoting the translocation of $\mathrm{Bcl}-2$ into the mitochondria, closing $\mathrm{mPTP}$, maintaining MMP, inhibiting the RIRR mechanism, suppressing oxidative stress, improving mitochondrial function, and alleviating adriamycin-induced endotheliotoxicity (Yang et al., 2019). Epirubicin is an isomer of adriamycin. TMP reverted epirubicin resistance by inhibiting the JAK2/STAT3 pathway and decreasing fibrinogen gamma chain (FGG) expression in breast cancer; the elimination of cancer stem cells has also been observed during this process (Liu et al., 2020).

\subsection{Cisplatin}

Cisplatin inhibits DNA function and cell mitosis (Hamano et al., 2021). Cisplatin has a wide antitumor spectrum and is used in the treatment of head and neck squamous cell carcinoma, ovarian cancer, embryonic cancer, lung cancer, and thyroid cancer (Fang et al., 2021; Prayuenyong et al., 2021). In Lewis lung cancer mice, TMP with cisplatin exhibited additional or synergistic effects with respect to inhibiting tumor growth effectively; the mechanism involved reducing the expression of the angiogenesis-promoting factor VEGF and increasing the expression of the angiogenesis inhibitors KLF4 and ADAMTS1 (Tang et al., 2017). Ai et al. (2016)-designed TMP-curcumin hybrids (10a-u). Compound $10 \mathrm{~d}$ inhibited the proliferation of the drug-sensitive lung cancer cell lines A549, SPC-A-1, and LTEP-G-2, and drug-resistant A549/ DDP cells, by suppressing the TrxR/Trx system and promoting intracellular ROS accumulation and cancer cell apoptosis. Compound $10 \mathrm{~d}$ also inhibited the growth of implanted human drug-resistant lung cancer in mice. TMP enhances the cytotoxic effect of antitumor agents on the bladder cancer cell lines Pumc-91/ $\mathrm{ADM}$ and T24/DDP in response to adriamycin, which results in cell cycle arrest in the G1/S phase due to the decrease in the levels of MRP1, GST, and Bcl-2 and increase in the levels of topoisomerase-II (Wang et al., 2016). Cisplatin is one of the most effective broadspectrum cancer chemotherapy drugs that exhibits serious adverse effects, such as acute renal injury. A study on cisplatin-treated rats showed that TMP might be a potential candidate for neoadjuvant chemotherapy due to its antioxidant, antiinflammatory, and antiapoptotic effects, in addition to its effect on Nrf2, the HMGB1/TLR4/NF- $\kappa B$ signaling pathway, and PPAR- $\gamma$ expression (Michel and Menze, 2019).

\subsection{Paclitaxel}

Paclitaxel, a natural secondary metabolite obtained from the bark of Taxus chinensis var. mairei via cell culture exhibits a good antitumor effect, particularly against ovarian (Lau et al., 2020), cervical (Kitagawa et al., 2015), and breast cancers (Untch et al., 2016). For the treatment of NSCLC, dequalinium-modified paclitaxel plus TMP micelles destroyed vasculogenic mimicry channels and inhibit tumor metastasis (Xie et al., 2019). In the ovarian cancer cell lines A2780 and SKOV3, TMP in combination with paclitaxel suppressed angiogenesis by inhibiting the ERK1/2 and Akt pathways and promoted the apoptosis of tumor cells to enhance the antitumor effects of paclitaxel compared with treatment alone. In A2780 xenograft mouse models, TMP augmented the antitumor effects of paclitaxel by influencing 
cell proliferation and angiogenesis as well as decreasing paclitaxel toxicity (Zou et al., 2019).

\section{DERIVATIVES AND COMPOUNDS OF TETRAMETHYLPYRAZINE}

Many active monomers used in traditional Chinese medicine and their derivatives or analogs can be used to overcome the low bioavailability of traditional Chinese medicines. They can ameliorate the clinical symptoms and prevent tumor recurrence. In addition, traditional Chinese medicine compounds can strengthen the antitumor effects (compared with single Chinese medicine monomers) (Luan et al., 2020). Below, we summarize the characteristics of three TMP derivatives and compounds [T-OA, DT-010, and (E)-2-(2-chlorostyryl)-3,5,6-trimethylpyrazine (CSTMP)] and expound their role in tumor treatment.

\subsection{T-OA}

$\mathrm{T}-\mathrm{OA}$, an antitumor TMP derivative with the chemical name 3ßhydroxyolea-12-en-28-oic acid-3,5,6-trimethylpyrazin-2methylester, has been shown to have effective anticancer activity (Fu et al., 2017). It exerts its antitumor activity and pharmacokinetic characteristics by preventing the expression of the nuclear transcription factor NF-kB/p65 and COX-2 in S180 mice (sarcoma) (Wang et al., 2013). Compared with cisplatin, T-OA is more toxic to the HCC cell line Bel-7402 than to three other cancer cell lines (HeLa, HT29 , and BGC-823), and plays a role in apoptosis by preventing the expression of NF- $\mathrm{kB} / \mathrm{p} 65$ and COX-2 in Bel-7402 cells (Zhang et al,, 2015). Although the poor solubility of T-OA results in low oral bioavailability, T-OA liposomes could significantly promote its intestinal lymphatic transport and enhance its oral bioavailability (Li et al., 2020). T-OA(6a), as a T-OA derivative designed by Chu et al. (2014), induced apoptosis in the HCC cell line HepG2 via nuclear fragmentation and exhibited lower nephrotoxicity. Additionally, T-OA(6a) exhibited good levels of cytotoxicity and possessed better hydrophilicity than T-OA in the cancer cell lines HepG2, HT-29, HeLa, and BGC-823 (Chu et al., 2014).

\subsection{DT-010}

DT-010, a novel synthetic compound of Danshensu and TMP, has been found to possess a cardioprotective effect with respect to myocardial ischemia/reperfusion injury in clinical studies (Xie et al., 2021). In the breast cell line MCF-7, DT-010 was more potent than TMP, Danshensu, or a combination of the two with respect to potentiating doxorubicin-induced toxicity; cotreatment with DT-010 and doxorubicin increased the level of apoptosis relative to doxorubicin alone. DT-010 and doxorubicin exhibit a synergistic antitumor effect in breast cancer by downregulating the glycolytic pathway and GRP78. DT-010 also protects against doxorubicin-induced cardiotoxicity (Wang et al., 2016), restores doxorubicin-induced apoptosis, and significantly inhibits growth when combined with doxorubicin. DT-010 overcomes doxorubicin resistance through a dual action by simultaneously inhibiting P-gpmediated drug efflux and influencing the metabolic process (Zhou et al., 2019). DT-010 potently inhibits cell proliferation by inducing cytotoxicity and promoting cell cycle arrest in the breast cancer cell lines MCF-7 and MDA-MB-231; this effect is attributed to the suppression of the mitochondrial function. Further studies have shown that DT-010 suppresses succinate-induced mitochondrial respiration and impairs mitochondrial complex II enzyme activity to trigger ROS generation and mitochondrial dysfunction (Wang et al., 2016). Tang et al. (2018) suggested DT-010 as a potential therapeutic agent for effectively combating the cardiotoxicity of doxorubicin. DT-010 prevents doxorubicin-induced morphological changes and directly inhibits the generation of ROS. As cardiotoxicity is multifactorial, DT-010 could also inhibit the induction of autophagosome formation by regulating the upstream Akt/AMPK/mTOR signaling pathway (Tang et al., 2018).

\subsection{CSTMP}

CSTMP, a TMP analog, was designed and synthesized based on the pharmacophores of TMP and resveratrol (Ding et al., 2016). In the lung cancer cell line A549, CSTMP inhibited cell proliferation and induced cell cycle arrest and apoptosis through IRE1a-TRAF2ASK1 complex-mediated ER stress, JNK activation, and mitochondrial dysfunction. The process could also be reversed by treatment with IRE1a siRNA (Zhang et al., 2016). CSTMP showed significant cytotoxic effects in the human myeloma cell line RPMI8226 by promoting caspase- and mitochondria-dependent apoptosis with increasing expressions of endoplasmic reticulum stress-related proteins (CHOP, GRP78, GRP94, and cleaved caspase-12) and activation of multiple ER stress transducers (PERK-eIF2 $\alpha$, IRE1 $\alpha$, and ATF6) (Sun et al., 2016).

Certain synthesized derivatives or compounds exhibit superior anticancer effects and fewer adverse effects than the available chemotherapeutic drugs or TMP monomers. These advantages are attributed to their relatively improved biosafety and lower toxicity, and successfully targeting proliferation, apoptosis, invasion, angiogenesis, cell cycle, and mitochondrial membrane potential. Synthetic TMP-betulin derivatives (TBs) have been proposed, with most demonstrating a better antitumor activity than betulin in HeLa, HepG2, BGC-823, and HT-29 cell lines. Among them, compound TB-01 showed the best antitumor effect and the lowest toxicity on normal cells, and demonstrated better cytotoxicity than cisplatin toward cancer cells. In addition, TB-01 induced early apoptosis in HepG2 cells and blocked the cell cycle at the G1 phase (Guo et al., 2020). Xu et al. (2015) designed novel TMP-triterpene derivatives, among which compound 4a exhibited better cytotoxic activity against Bel-7402, HT-29, MCF-7, HeLa, and HepG2 than cisplatin by depolarizing the mitochondrial membrane potential and increasing the intracellular free $\mathrm{Ca}^{2+}$ concentration (Xu et al., 2015). Dipeptide derivatives of TBA (a TMP compound) and amino acid were also designed by Xu et al. (2017), of which BA-25 exhibited the highest cytotoxic activity in tumor cell lines (HepG2, HT-29, HeLa, BCG-823, and A549) compared with cisplatin. BA-25 induced apoptosis associated with loss of mitochondrial membrane potential and increased intracellular free $\mathrm{Ca}^{2+}$ concentration (Xu et al., 2017). Wang et al. (2012) applied the "combination principle" in drug discovery and used several effective antitumor ingredients of Shi Quan $\mathrm{Da} \mathrm{Bu}$ Wan as starting materials to synthesize TMP derivatives, which showed antiproliferative activities against 
HCT-8, Bel-7402, BGC-823, A-549, and A2780 human cancer cell lines and suppressed normal angiogenesis (Wang et al., 2012).

\section{CLINICAL TRIALS IN TUMOR TREATMENT}

To overcome the clinical applications of TMP in tumor treatment, clinical trials remain essential. Most of the aforementioned treatment modalities of tumors involving TMP remain on the cellular and animal stage. Data obtained from human experiments remain limited (Table 1). Yang et al. (2010) administered intravenous TMP infusions to 56 patients with NHL in conjunction with chemotherapy with an application dose of $5 \mathrm{mg} / \mathrm{kg}$ and a maximum dose of $400 \mathrm{mg} /$ day. Chen et al. (1997) combined $80 \mathrm{mg}$ of TMP and 5\% GS for intravenous infusion to affect platelet function and the coagulation state in 38 patients with lung cancer at a rate of $60-70 \mathrm{drops} / \mathrm{min}$. These two studies suggest the potential use of TMP as an antitumor agent. Research on the antitumor effects of TMP requires the cooperation of various research organizations, which will promote the development of TMP-related drugs, improve its safety and treatment outcomes.

\section{CONCLUSION AND FUTURE PERSPECTIVES}

Several preclinical and clinical studies have independently verified that TMP exhibits chemical prevention and treatment

\section{REFERENCES}

Ai, Y., Zhu, B., Ren, C., Kang, F., Li, J., Huang, Z., et al. (2016). Discovery of New Monocarbonyl Ligustrazine-Curcumin Hybrids for Intervention of DrugSensitive and Drug-Resistant Lung Cancer. J. Med. Chem. 59, 1747-1760. doi:10.1021/acs.jmedchem.5b01203

Bach, P. B. (2009). Smoking as a Factor in Causing Lung Cancer. JAMA 301, 539-541. doi:10.1001/jama.2009.57

Bi, L., Yan, X., Chen, W., Gao, J., Qian, L., and Qiu, S. (2016). Antihepatocellular Carcinoma Potential of Tetramethylpyrazine Induces Cell Cycle Modulation and Mitochondrial-dependent Apoptosis: Regulation of P53 Signaling Pathway in Hepg2 Cells In Vitro. Integr. Cancer Ther. 15, 226-236. doi:10.1177/ 1534735416637424

Bian, Y., Yang, L., Sheng, W., Li, Z., Xu, Y., Li, W., et al. (2021). Ligustrazine Induces the Colorectal Cancer Cells Apoptosis via P53-dependent Mitochondrial Pathway and Cell Cycle Arrest at the G0/g1 Phase. Ann. Palliat. Med. 10, 1578-1588. doi:10.21037/apm-20-288

Cai, X., Chen, Z., Pan, X., Xia, L., Chen, P., Yang, Y., et al. (2014). Inhibition of Angiogenesis, Fibrosis and Thrombosis by Tetramethylpyrazine: Mechanisms Contributing to the Sdf-1/cxcr4 axis. PloS one 9, e88176. doi:10.1371/ journal.pone.0088176

Cao, J., Miao, Q., Miao, S., Bi, L., Zhang, S., Yang, Q., et al. (2015). Tetramethylpyrazine (Tmp) Exerts Antitumor Effects by Inducing Apoptosis and Autophagy in Hepatocellular Carcinoma. Int. Immunopharmacol 26, 212-220. doi:10.1016/j.intimp.2015.03.028

Cao, J., Miao, Q., Zhang, J., Miao, S., Bi, L., Zhang, S., et al. (2015). Inhibitory Effect of Tetramethylpyrazine on Hepatocellular Carcinoma: Possible Role of Apoptosis and Cell Cycle Arrest. J. Biol. Regul. Homeost Agents 29, 297-306. potential for various cancers. Therefore, based on the above results, we can suggest factors that have led to the antitumor activity of TMP (Figure 3 and Table 2). However, there remains a need for sufficient evidence to continue to study the exact antitumor mechanism underlying the role of TMP and promote its clinical application in the treatment of cancer. Therefore, future research should focus on elucidating the precise anticancer mechanism underlying the role of TMP. Studies should continue to investigate MDR and TMP from various aspects and targets, to explain their mechanisms, as well as to evaluate the safety and effectiveness of TMP to facilitate its clinical application.

\section{AUTHOR CONTRIBUTIONS}

SY, SW, and JK designed the study and revised the manuscript. WD, LP, YX, TR, XZ, SB, YZ, JW, YS, and ZZ performed the literature search. SY drafted the manuscript. All authors contributed to the article and approved the submitted version.

\section{FUNDING}

The present study was supported by the Shenyang Science and Technology Innovation Talent Support Program for Youth and Midlife (grant no. RC200121) and The 345 Talent Project Program of China Medical University Shengjing Hospital (grant no. 2019-40A).

Cao, W., Chen, H. D., Yu, Y. W., Li, N., and Chen, W. Q. (2021). Changing Profiles of Cancer burden Worldwide and in china: A Secondary Analysis of the Global Cancer Statistics 2020. Chin. Med. J. (Engl) 134, 783-791. doi:10.1097/ CM9.0000000000001474

Cartel, M., Mouchel, P. L., Gotanègre, M., David, L., Bertoli, S., Mansat-De Mas, V., et al. (2021). Inhibition of Ubiquitin-specific Protease 7 Sensitizes Acute Myeloid Leukemia to Chemotherapy. Leukemia 35, 417-432. doi:10.1038/ s41375-020-0878-x

Chen, J., Wang, W., Wang, H., Liu, X., and Guo, X. (2014). Combination Treatment of Ligustrazine Piperazine Derivate Dlj14 and Adriamycin Inhibits Progression of Resistant Breast Cancer through Inhibition of the Egfr/pi3k/akt Survival Pathway and Induction of Apoptosis. Drug Discov. Ther. 8, 33-41. doi:10.5582/ddt.8.33

Chen, L., Lu, Y., Wu, J. M., Xu, B., Zhang, L. J., Gao, M., et al. (2009). Ligustrazine Inhibits B16f10 Melanoma Metastasis and Suppresses Angiogenesis Induced by Vascular Endothelial Growth Factor. Biochem. Biophys. Res. Commun. 386, 374-379. doi:10.1016/j.bbrc.2009.06.042

Chen, L. H., Pan, C., Diplas, B. H., Xu, C., Hansen, L. J., Wu, Y., et al. (2020). The Integrated Genomic and Epigenomic Landscape of Brainstem Glioma. Nat. Commun. 11, 3077. doi:10.1038/s41467-020-16682-y

Chen, S. X., Wang, L. X., and Xing, L. L. (1997). Effects of Tetramethylpyrazine on Platelet Functions of Advanced Cases of Lung Carcinoma. Zhongguo Zhong Xi Yi Jie He Za Zhi 17, 531-533.

Chen, Z., Pan, X., Georgakilas, A. G., Chen, P., Hu, H., Yang, Y., et al. (2013). Tetramethylpyrazine (Tmp) Protects Cerebral Neurocytes and Inhibits Glioma by Down Regulating Chemokine Receptor Cxcr4 Expression. Cancer Lett. 336, 281-289. doi:10.1016/j.canlet.2013.03.015

Cheng, X. R., Zhang, L., Hu, J. J., Sun, L., and Du, G. H. (2007). Neuroprotective Effects of Tetramethylpyrazine on Hydrogen Peroxide-Induced Apoptosis in Pc12 Cells. Cell Biol Int 31, 438-443. doi:10.1016/j.cellbi.2006.10.001 
Chu, F., Xu, X., Li, G., Gu, S., Xu, K., Gong, Y., et al. (2014). Amino Acid Derivatives of Ligustrazine-Oleanolic Acid as New Cytotoxic Agents. Molecules 19, 18215-18231. doi:10.3390/molecules191118215

Collaborators, G. M. a. C. o. D. (2015). Global, Regional, and National Age-Sex Specific All-Cause and Cause-specific Mortality for 240 Causes of Death, 19902013: A Systematic Analysis for the Global burden of Disease Study 2013. Lancet (London, England) 385, 117-171. doi:10.1016/S0140-6736(14)61682-2

Cornford, P., van den Bergh, R. C. N., Briers, E., Van den Broeck, T., Cumberbatch, M. G., De Santis, M., et al. (2021). Eau-eanm-estro-esur-siog Guidelines on Prostate Cancer. Part Ii-2020 Update: Treatment of Relapsing and Metastatic Prostate Cancer. Eur. Urol. 79, 263-282. doi:10.1016/j.eururo.2020.09.046

Cui, H., Guo, W., Zhang, B., Li, G., Li, T., Yuan, Y., et al. (20202019). Correction: Cui, H., et al. BA-12 Inhibits Angiogenesis via Glutathione Metabolism Activation. Int. J. Mol. Sci. 2019, 20, 4062. Int. J. Mol. Sci. 21, 4062. doi:10.3390/ijms21186814

Cui, H., Guo, W., Zhang, B., Li, G., Li, T., Yuan, Y., et al. (2019). Ba-12 Inhibits Angiogenesis via Glutathione Metabolism Activation. Ijms 20, 4062. doi:10.3390/ijms20164062

Ding, Y., Liao, W., He, X., Xiang, W., and Lu, Q. (2016). CSTMP Exerts Antiinflammatory Effects on LPS-Induced Human Renal Proximal Tubular Epithelial Cells by Inhibiting TLR4-Mediated NF-Kb Pathways. Inflammation 39, 849-859. doi:10.1007/s10753-016-0315-5

Eslahi, M., Dana, P. M., Asemi, Z., Hallajzadeh, J., Mansournia, M. A., and Yousefi, B. (2021). The Effects of Chitosan-Based Materials on Glioma: Recent Advances in its Applications for Diagnosis and Treatment. Int. J. Biol. Macromol 168, 124-129. doi:10.1016/j.ijbiomac.2020.11.180

Fan, C., Wang, Y., Huang, H., Li, W., Ma, J., Yao, D., et al. (2021). The Tetramethylpyrazine Derivative Statmp-151: A Novel Small Molecule Stat3 Inhibitor with Promising Activity against Breast Cancer. Front. Pharmacol. 12, 651976. doi:10.3389/fphar.2021.651976

Fang, C.-Y., Lou, D.-Y., Zhou, L.-Q., Wang, J.-C., Yang, B., He, Q.-J., et al. (2021). Natural Products: Potential Treatments for Cisplatin-Induced Nephrotoxicity. Acta Pharmacol. Sin. doi:10.1038/s41401-021-00620-9

Feng, L., Mao, W., Zhang, J., Liu, X., Jiao, Y., Zhao, X., et al. (2014). Pharmacokinetic Variations of Tetramethylpyrazine Phosphate after Oral Administration in Hepatic Precancerous Mice and its Hepatoprotective Effects. Drug Dev. Ind. Pharm. 40, 1-8. doi:10.3109/03639045.2012.756513

Fu, J., Dong, X. X., Zeng, Z. P., Yin, X. B., Li, F. W., and Ni, J. (2017). Preparation and Physicochemical Characterization of T-Oa Plga Microspheres. Chin. J. Nat. Med. 15, 912-916. doi:10.1016/S1875-5364(18)30007-4

Fu, Y. S., Lin, Y. Y., Chou, S. C., Tsai, T. H., Kao, L. S., Hsu, S. Y., et al. (2008). Tetramethylpyrazine Inhibits Activities of Glioma Cells and Glutamate NeuroExcitotoxicity: Potential Therapeutic Application for Treatment of Gliomas. Neuro Oncol. 10, 139-152. doi:10.1215/15228517-2007-051

Gao, Y., Xu, C., Liang, S., Zhang, A., Mu, S., Wang, Y., et al. (2008). Effect of Tetramethylpyrazine on Primary Afferent Transmission Mediated by $\mathrm{P} 2 \times 3$ Receptor in Neuropathic Pain States. Brain Res. Bull. 77, 27-32. doi:10.1016/ j.brainresbull.2008.02.026

Gong, X., Ivanov, V. N., Davidson, M. M., and Hei, T. K. (2015). Tetramethylpyrazine (Tmp) Protects against Sodium Arsenite-Induced Nephrotoxicity by Suppressing Ros Production, Mitochondrial Dysfunction, Pro-inflammatory Signaling Pathways and Programed Cell Death. Arch. Toxicol. 89, 1057-1070. doi:10.1007/s00204-014-1302-y

Guan, D., Su, Y., Li, Y., Wu, C., Meng, Y., Peng, X., et al. (2015). Tetramethylpyrazine Inhibits $\mathrm{CoCl} 2$-induced Neurotoxicity through Enhancement of Nrf2/GCLc/GSH and Suppression of HIF1a/NOX2/ROS Pathways. J. Neurochem. 134, 551-565. doi:10.1111/jnc.13161

Guo, M., Liu, Y., and Shi, D. (2016). Cardiovascular Actions and Therapeutic Potential of Tetramethylpyrazine (Active Component Isolated from Rhizoma Chuanxiong): Roles and Mechanisms. Biomed. Res. Int. 2016, 2430329. doi:10.1155/2016/2430329

Guo, W. B., Zhang, H., Yan, W. Q., Liu, Y. M., Zhou, F., Cai, D. S., et al. (2020). Design, Synthesis, and Biological Evaluation of Ligustrazine - Betulin AminoAcid/dipeptide Derivatives as Anti-tumor Agents. Eur. J. Med. Chem. 185, 111839. doi:10.1016/j.ejmech.2019.111839

Hamano, H., Ikeda, Y., Goda, M., Fukushima, K., Kishi, S., Chuma, M., et al. (2021). Diphenhydramine May Be a Preventive Medicine against
Cisplatin-Induced Kidney Toxicity. Kidney Int. 99, 885-899. doi:10.1016/j.kint.2020.10.041

Han, J., Song, J., Li, X., Zhu, M., Guo, W., Xing, W., et al. (2015). Ligustrazine Suppresses the Growth of Hrpc Cells through the Inhibition of Cap-Dependent Translation via Both the Mtor and the Mek/erk Pathways. Anticancer Agents Med. Chem. 15, 764-772. doi:10.2174/1871520615666150305112120

Heber, S., Sallaberger-Lehner, M., Hausharter, M., Volf, I., Ocenasek, H., Gabriel, H., et al. (2019). Exercise-based Cardiac Rehabilitation Is Associated with a Normalization of the Heart Rate Performance Curve Deflection. Scand. J. Med. Sci. Sports 29, 1364-1374. doi:10.1111/sms.13462

Herbst, R. S., Morgensztern, D., and Boshoff, C. (2018). The Biology and Management of Non-small Cell Lung Cancer. Nature 553, 446-454. doi:10.1038/nature25183

Hirsch, F. R., Scagliotti, G. V., Mulshine, J. L., Kwon, R., Curran, W. J., Wu, Y. L., et al. (2017). Lung Cancer: Current Therapies and New Targeted Treatments. Lancet 389, 299-311. doi:10.1016/S0140-6736(16)30958-8

Holohan, C., Van Schaeybroeck, S., Longley, D. B., and Johnston, P. G. (2013). Cancer Drug Resistance: An Evolving Paradigm. Nat. Rev. Cancer 13, 714-726. doi:10.1038/nrc3599

Hu, Y. P., Lin, J., Wang, Q. D., Yie, Q. X., and Zhang, T. M. (1993). Reversal of Adriamycin Resistance by Verapamil and Ligustrazini in Mouse Ehrlich Ascites Cancer. Yao Xue Xue Bao 28, 75-78.

Huang, H. H., Liu, F. B., Ruan, Z., Zheng, J., Su, Y. J., and Wang, J. (2018). Tetramethylpyrazine (Tmpz) Triggers S-phase Arrest and Mitochondriadependent Apoptosis in Lung Cancer Cells. Neoplasma 65, 367-375. doi:10.4149/neo_2018_170112N26

Ishida, T., Takechi, S., and Yamaguchi, T. (2012). Possible Involvement of Glutathione Balance Disruption in Dihydropyrazine-Induced Cytotoxicity on Human Hepatoma Hepg2 Cells. J. Toxicol. Sci. 37, 1065-1069. doi:10.2131/jts.37.1065

Islami, F., Chen, W., Yu, X. Q., Lortet-Tieulent, J., Zheng, R., Flanders, W. D., et al. (2017). Cancer Deaths and Cases Attributable to Lifestyle Factors and Infections in china, 2013. Ann. Oncol. 28, 2567-2574. doi:10.1093/annonc/ $\operatorname{mdx} 342$

Ji, A. J., Liu, S. L., Ju, W. Z., and Huang, X. E. (2014). Anti-proliferation Effects and Molecular Mechanisms of Action of Tetramethypyrazine on Human Sgc-7901 Gastric Carcinoma Cells. Asian Pac. J. Cancer Prev. 15, 3581-3586. doi:10.7314/ apjcp.2014.15.8.3581

Jia, Y., Wang, Z., Zang, A., Jiao, S., Chen, S., and Fu, Y. (2016). Tetramethylpyrazine Inhibits Tumor Growth of Lung Cancer through Disrupting Angiogenesis via Bmp/smad/id-1 Signaling. Int. J. Oncol. 48, 2079-2086. doi:10.3892/ ijo.2016.3443

Jiao, Y., Zhang, S., Zhang, J., and Du, J. (2019). Tetramethylpyrazine Attenuates Placental Oxidative Stress, Inflammatory Responses and Endoplasmic Reticulum Stress in a Mouse Model of Gestational Diabetes Mellitus. Arch. Pharm. Res. 42, 1092-1100. doi:10.1007/s12272-019-01197-y

Jonasch, E., Walker, C. L., and Rathmell, W. K. (2021). Clear Cell Renal Cell Carcinoma Ontogeny and Mechanisms of Lethality. Nat. Rev. Nephrol. 17, 245-261. doi:10.1038/s41581-020-00359-2

Kim, M., Kim, S. O., Lee, M., Lee, J. H., Jung, W. S., Moon, S. K., et al. (2014). Tetramethylpyrazine, a Natural Alkaloid, Attenuates Pro-inflammatory Mediators Induced by Amyloid $\beta$ and Interferon- $\gamma$ in Rat Brain Microglia. Eur. J. Pharmacol. 740, 504-511. doi:10.1016/j.ejphar.2014.06.037

Kitagawa, R., Katsumata, N., Shibata, T., Kamura, T., Kasamatsu, T., Nakanishi, T., et al. (2015). Paclitaxel Plus Carboplatin versus Paclitaxel Plus Cisplatin in Metastatic or Recurrent Cervical Cancer: The Open-Label Randomized Phase Iii Trial Jcog0505. J. Clin. Oncol. 33, 2129-2135. doi:10.1200/JCO.2014.58.4391

Lau, T. S., Chan, L. K. Y., Man, G. C. W., Wong, C. H., Lee, J. H. S., Yim, S. F., et al. (2020). Paclitaxel Induces Immunogenic Cell Death in Ovarian Cancer via Tlr4/ ikk2/snare-dependent Exocytosis. Cancer Immunol. Res. 8, 1099-1111. doi:10.1158/2326-6066.CIR-19-0616

Li, H., Yang, X., Shi, W., Ma, Z., Feng, G. K., Yin, Y. L., et al. (2015). Protective Effects of Tetramethylpyrazine on Cerebrovascular Regulations in Rats with Chronic Alcoholic Encephalopathy. Biomed. Environ. Sci. 28, 691-695. doi:10.3967/bes2015.098

Li, L. L., Zhang, Z. R., Gong, T., He, L. L., and Deng, L. (2006). Simultaneous Determination of Gastrodin and Ligustrazine Hydrochloride in Dog Plasma by 
Gradient High-Performance Liquid Chromatography. J. Pharm. Biomed. Anal. 41, 1083-1087. doi:10.1016/j.jpba.2006.02.023

Li, Q. W., Zhang, G. L., Hao, C. X., Ma, Y. F., Sun, X., Zhang, Y., et al. (2021). Sant, a Novel Chinese Herbal Monomer Combination, Decreasing Tumor Growth and Angiogenesis via Modulating Autophagy in Heparanase Overexpressed TripleNegative Breast Cancer. J. Ethnopharmacol 266, 113430. doi:10.1016/ j.jep. 2020.113430

Li, S., Jin, S., Wang, X., Song, N., Wang, P., Chen, F., et al. (2020). Intestinal Lymphatic Transport Study of Antitumor lead Compound T-Oa with Liposomes. Pak J. Pharm. Sci. 33, 631-640.

Li, W., Luo, L., Shi, W., Yin, Y., and Gao, S. (2021). Ursolic Acid Reduces Adriamycin Resistance of Human Ovarian Cancer Cells through Promoting the Hur Translocation from Cytoplasm to Nucleus. Environ. Toxicol. 36, 267-275. doi:10.1002/tox.23032

Li, Y., Dong, X., Yin, Y., Su, Y., Xu, Q., Zhang, Y., et al. (2005). Bj-tsa-9, a Novel Human Tumor-specific Gene, Has Potential as a Biomarker of Lung Cancer. Neoplasia 7, 1073-1080. doi:10.1593/neo.05406

Li, Z., Yulei, J., Yaqing, J., Jinmin, Z., Xinyong, L., Jing, G., et al. (2019). Protective Effects of Tetramethylpyrazine Analogue Z-11 on Cerebral Ischemia Reperfusion Injury. Eur. J. Pharmacol. 844, 156-164. doi:10.1016/ j.ejphar.2018.11.031

Liang, S. D., Xu, C. S., Zhou, T., Liu, H. Q., Gao, Y., and Li, G. L. (2005). Tetramethylpyrazine Inhibits Atp-Activated Currents in Rat Dorsal Root Ganglion Neurons. Brain Res. 1040, 92-97. doi:10.1016/j.brainres.2005.01.076

Liu, Y. L., Yan, Z. X., Xia, Y., Xie, X. Y., Zhou, K., Xu, L. L., et al. (2020). Ligustrazine Reverts Anthracycline Chemotherapy Resistance of Human Breast Cancer by Inhibiting Jak2/stat3 Signaling and Decreasing Fibrinogen Gamma Chain (Fgg) Expression. Am. J. Cancer Res. 10, 939-952.

Luan, X., Zhang, L. J., Li, X. Q., Rahman, K., Zhang, H., Chen, H. Z., et al. (2020). Compound-based Chinese Medicine Formula: From Discovery to Compatibility Mechanism. J. Ethnopharmacol 254, 112687. doi:10.1016/ j.jep.2020.112687

Luan, Y., Liu, J., Liu, X., Xue, X., Kong, F., Sun, C., et al. (2016). Tetramethypyrazine Inhibits Renal Cell Carcinoma Cells through Inhibition of Nkg2d Signaling Pathways. Int. J. Oncol. 49, 1704-1712. doi:10.3892/ijo.2016.3670

Ma, X., Ruan, Q., Ji, X., Yang, J., and Peng, H. (2021). Ligustrazine Alleviates Cyclophosphamide-Induced Hepatotoxicity via the Inhibition of Txnip/Trx/ NF-Kb Pathway. Life Sci. 274, 119331. doi:10.1016/j.lfs.2021.119331

Mei, Y., Shi, Y. J., Zuo, G. Q., Gong, J. P., Liu, C. A., Li, X. H., et al. (2004). Study on Ligustrazine in Reversing Multidrug Resistance of Hepg2/adm Cell In Vitro. Zhongguo Zhong Yao Za Zhi 29, 970-973.

Michel, H. E., and Menze, E. T. (2019). Tetramethylpyrazine Guards against Cisplatin-Induced Nephrotoxicity in Rats through Inhibiting HMGB1/TLR4/ $\mathrm{NF}-\mathrm{Kb}$ and Activating Nrf2 and PPAR- $\gamma$ Signaling Pathways. Eur. J. Pharmacol. 857, 172422. doi:10.1016/j.jphar.2019.172422

Miller, K. D., Fidler-Benaoudia, M., Keegan, T. H., Hipp, H. S., Jemal, A., and Siegel, R. L. (2020). Cancer Statistics for Adolescents and Young Adults, 2020. CA Cancer J. Clin. 70, 443-459. doi:10.3322/caac.2159010.3322/caac.21637

Pan, J., Shang, J. F., Jiang, G. Q., and Yang, Z. X. (2015). Ligustrazine Induces Apoptosis of Breast Cancer Cells In Vitro and In Vivo. J. Cancer Res. Ther. 11, 454-458. doi:10.4103/0973-1482.147378

Perboni, G., Costa, P., Fibbia, G. C., Morandini, B., Scalzini, A., Tagliani, A., et al. (2010). Sorafenib Therapy for Hepatocellular Carcinoma in an Hiv-Hcv Coinfected Patient: A Case Report. Oncologist 15, 142-145. doi:10.1634/ theoncologist.2010-0010

Prayuenyong, P., Baguley, D. M., Kros, C. J., and Steyger, P. S. (2021). Preferential Cochleotoxicity of Cisplatin. Front. Neurosci. 15, 695268. doi:10.3389/ fnins.2021.695268

Qian, W., Xiong, X., Fang, Z., Lu, H., and Wang, Z. (20142014). Protective Effect of Tetramethylpyrazine on Myocardial Ischemia-Reperfusion Injury. Evid. Based Complement. Alternat Med. 2014, 107501. doi:10.1155/2014/107501

Raaschou-Nielsen, O., Andersen, Z. J., Beelen, R., Samoli, E., Stafoggia, M., Weinmayr, G., et al. (2013). Air Pollution and Lung Cancer Incidence in 17 European Cohorts: Prospective Analyses from the European Study of Cohorts for Air Pollution Effects (Escape). Lancet Oncol. 14, 813-822. doi:10.1016/ S1470-2045(13)70279-1

Riaz, I. B., and Hussain, S. A. (2021). Perioperative Treatment in Muscle-Invasive Bladder Cancer: Analysis of Secondary Endpoints in a Randomized Trial
Comparing Gemcitabine and Cisplatin versus Dose-Dense Methotrexate, Vinblastine, Adriamycin, and Cisplatin. Eur. Urol. 79, 222-224. doi:10.1016/ j.eururo.2020.09.018

Shan Au, A. L., Kwan, Y. W., Kwok, C. C., Zhang, R. Z., and He, G. W. (2003). Mechanisms Responsible for the In Vitro Relaxation of Ligustrazine on Porcine Left Anterior Descending Coronary Artery. Eur. J. Pharmacol. 468, 199-207. doi:10.1016/s0014-2999(03)01691-1

Shen, J., Zeng, L., Pan, L., Yuan, S., Wu, M., and Kong, X. (2018). Tetramethylpyrazine Regulates Breast Cancer Cell Viability, Migration, Invasion and Apoptosis by Affecting the Activity of Akt and Caspase-3. Oncol. Lett. 15, 4557-4563. doi:10.3892/ol.2018.7851

Shiffman, M. L. (2018). The Next Wave of Hepatitis C Virus: The Epidemic of Intravenous Drug Use. Liver Int. 38 Suppl 1 (Suppl. 1), 34-39. doi:10.1111/ liv. 13647

Snijders, A. M., Lee, S. Y., Hang, B., Hao, W., Bissell, M. J., and Mao, J. H. (2017). Fam83 Family Oncogenes Are Broadly Involved in Human Cancers: An Integrative Multi-Omics Approach. Mol. Oncol. 11, 167-179. doi:10.1002/ 1878-0261.12016

Song, Y. N., Guo, X. L., Zheng, B. B., Liu, X. Y., Dong, X., Yu, L. G., et al. (2011). Ligustrazine Derivate DLJ14 Reduces Multidrug Resistance of K562/A02 Cells by Modulating GST $\pi$ Activity. Toxicol. Vitro 25, 937-943. doi:10.1016/ j.tiv.2011.03.002

Sun, W., Li, A., Wang, Z., Sun, X., Dong, M., Qi, F., et al. (2020). Tetramethylpyrazine Alleviates Acute Kidney Injury by Inhibiting NLRP3/ HIF-1a and A-poptosis. Mol. Med. Rep. 22, 2655-2664. doi:10.3892/ mmr.2020.11378

Sun, X., Liao, W., Wang, J., Wang, P., Gao, H., Wang, M., et al. (2016). Cstmp Induces Apoptosis and Mitochondrial Dysfunction in Human Myeloma Rpmi8226 Cells via Chop-dependent Endoplasmic Reticulum Stress. Biomed. Pharmacother. 83, 776-784. doi:10.1016/j.biopha.2016.07.045

Sung, H., Ferlay, J., Siegel, R. L., Laversanne, M., Soerjomataram, I., Jemal, A., et al. (2021). Global Cancer Statistics 2020: Globocan Estimates of Incidence and Mortality Worldwide for 36 Cancers in 185 Countries. CA Cancer J. Clin. 71, 209-249. doi:10.3322/caac.21660

Tang, F., Zhou, X., Wang, L., Shan, L., Li, C., Zhou, H., et al. (2018). A Novel Compound Dt-010 Protects against Doxorubicin-Induced Cardiotoxicity in Zebrafish and H9c2 Cells by Inhibiting Reactive Oxygen Species-Mediated Apoptotic and Autophagic Pathways. Eur. J. Pharmacol. 820, 86-96. doi:10.1016/j.ejphar.2017.12.021

Tang, J. H., Zhang, H. M., Zhang, Z. H., and Zhang, X. L. (2017). Effect of Tetramethylpyrazine Combined with Cisplatin on Vegf, Klf4 and Adamts1 in lewis Lung Cancer Mice. Asian Pac. J. Trop. Med. 10, 813-818. doi:10.1016/ j.apjtm.2017.08.001

Thun, M. J., Carter, B. D., Feskanich, D., Freedman, N. D., Prentice, R., Lopez, A. D., et al. (2013). 50-year Trends in Smoking-Related Mortality in the united states. N. Engl. J. Med. 368, 351-364. doi:10.1056/NEJMsa1211127

Tian, Y., Liu, Y., Chen, X., Zhang, H., Shi, Q., Zhang, J., et al. (2010). Tetramethylpyrazine Promotes Proliferation and Differentiation of Neural Stem Cells from Rat Brain in Hypoxic Condition via Mitogen-Activated Protein Kinases Pathway In Vitro. Neurosci. Lett. 474, 26-31. doi:10.1016/ j.neulet.2010.02.066

Tinoush, B., Shirdel, I., and Wink, M. (2020). Phytochemicals: Potential lead Molecules for Mdr Reversal. Front. Pharmacol. 11, 832. doi:10.3389/ fphar.2020.00832

Tran, B., and Bedard, P. L. (2011). Luminal-b Breast Cancer and Novel Therapeutic Targets. Breast Cancer Res. 13, 221. doi:10.1186/bcr2904

Ubellacker, J. M., Tasdogan, A., Ramesh, V., Shen, B., Mitchell, E. C., MartinSandoval, M. S., et al. (2020). Lymph Protects Metastasizing Melanoma Cells from Ferroptosis. Nature 585, 113-118. doi:10.1038/s41586-020-2623-z

Untch, M., Jackisch, C., Schneeweiss, A., Conrad, B., Aktas, B., Denkert, C., et al. (2016). Nab-paclitaxel versus Solvent-Based Paclitaxel in Neoadjuvant Chemotherapy for Early Breast Cancer (Geparsepto-gbg 69): A Randomised, Phase 3 Trial. Lancet Oncol. 17, 345-356. doi:10.1016/S1470-2045(15)00542-2

Viale, G., Hanlon Newell, A. E., Walker, E., Harlow, G., Bai, I., Russo, L., et al. (2019). Ki-67 (30-9) Scoring and Differentiation of Luminal a- and Luminal B-like Breast Cancer Subtypes. Breast Cancer Res. Treat. 178, 451-458. doi:10.1007/s10549-019-05402-w 
Viedma-Rodríguez, R., Baiza-Gutman, L., Salamanca-Gómez, F., Diaz-Zaragoza, M., Martínez-Hernández, G., Ruiz Esparza-Garrido, R., et al. (2014). Mechanisms Associated with Resistance to Tamoxifen in Estrogen ReceptorPositive Breast Cancer (Review). Oncol. Rep. 32, 3-15. doi:10.3892/ or.2014.3190

Wang, C., Li, Y., Yang, X., Bi, S., Zhang, Y., Han, D., et al. (2017). Tetramethylpyrazine and Astragaloside Iv Synergistically Ameliorate Left Ventricular Remodeling and Preserve Cardiac Function in a Rat Myocardial Infarction Model. J. Cardiovasc. Pharmacol. 69, 34-40. doi:10.1097/ FJC.0000000000000437

Wang, J., Hong, G., Li, G., Wang, W., and Liu, T. (2019). Novel Homo-Bivalent and Polyvalent Compounds Based on Ligustrazine and Heterocyclic Ring as Anticancer Agents. Molecules 24. doi:10.3390/molecules24244505

Wang, J. B., Jiang, Y., Liang, H., Li, P., Xiao, H. J., Ji, J., et al. (2012). Attributable Causes of Cancer in china. Ann. Oncol. 23, 2983-2989. doi:10.1093/annonc/ mds139

Wang, L., Chan, J. Y., Zhou, X., Cui, G., Yan, Z., Wang, L., et al. (2016). A Novel Agent Enhances the Chemotherapeutic Efficacy of Doxorubicin in Mcf-7 Breast Cancer Cells. Front. Pharmacol. 7, 249. doi:10.3389/fphar.2016.00249

Wang, L., Zhang, X., Cui, G., Chan, J. Y., Wang, L., Li, C., et al. (2016). A Novel Agent Exerts Antitumor Activity in Breast Cancer Cells by Targeting Mitochondrial Complex Ii. Oncotarget 7, 32054-32064. doi:10.18632/ oncotarget.8410

Wang, P., She, G., Yang, Y., Li, Q., Zhang, H., Liu, J., et al. (2012). Synthesis and Biological Evaluation of New Ligustrazine Derivatives as Anti-tumor Agents. Molecules 17, 4972-4985. doi:10.3390/molecules 17054972

Wang, P., Zhang, Y., Xu, K., Li, Q., Zhang, H., Guo, J., et al. (2013). A New Ligustrazine Derivative-Ppharmacokinetic Evaluation and Antitumor Activity by Suppression of Nf-Kappab/p65 and Cox-2 Expression in S180 Mice. Pharmazie 68, 782-789.

Wang, S., Lei, T., and Zhang, M. (2016). The Reversal Effect and its Mechanisms of Tetramethylpyrazine on Multidrug Resistance in Human Bladder Cancer. PloS one 11, e0157759. doi:10.1371/journal.pone.0157759

Wang, X., Tan, Y., Zhang, Y., Xu, Z., Xu, B., Lei, H., et al. (2020). The Novel Glycyrrhetinic Acid-Tetramethylpyrazine Conjugate Toga Induces Antihepatocarcinogenesis by Inhibiting the Effects of Tumor-Associated Macrophages on Tumor Cells. Pharmacol. Res. 161, 105233. doi:10.1016/ j.phrs.2020.105233

Wang, X. B., Wang, S. S., Zhang, Q. F., Liu, M., Li, H. L., Liu, Y., et al. (2010). Inhibition of Tetramethylpyrazine on P-Gp, Mrp2, Mrp3 and Mrp5 in Multidrug Resistant Human Hepatocellular Carcinoma Cells. Oncol. Rep. $23,211-215$.

Wang, X. J., Xu, Y. H., Yang, G. C., Chen, H. X., and Zhang, P. (2015). Tetramethylpyrazine Inhibits the Proliferation of Acute Lymphocytic Leukemia Cell Lines via Decrease in GSK-3 $\beta$. Oncol. Rep. 33, 2368-2374. doi:10.3892/or.2015.3860

Wang, X. J., Yang, G. C., Chen, H. X., Zhang, P., and Xu, Y. H. (2015). Study on Effect of Tetramethylpyrazine on Proliferation and Apoptosis of Leukemic U937 Cells and its Mechanism. Zhongguo Zhong Yao Za Zhi 40, 2186-2190.

Wang, Y., Fu, Q., and Zhao, W. (2013). Tetramethylpyrazine Inhibits Osteosarcoma Cell Proliferation via Downregulation of NF-Kb In Vitro and In Vivo. Mol. Med. Rep. 8, 984-988. doi:10.3892/mmr.2013.1611

Wei, H., Sun, R., Xiao, W., Feng, J., Zhen, C., Xu, X., et al. (2004). Type Two Cytokines Predominance of Human Lung Cancer and its Reverse by Traditional Chinese Medicine Ttmp. Cell Mol Immunol 1, 63-70.

Wei, H., Tian, Z., Xu, X., Feng, J., and Xiao, W. (2002). Expression of Transcription Factor T-Bet/gata3 in Lung Cancer Patients and its Interference by the Traditional Chinese Herbal Medicine. Zhonghua Zhong Liu Za Zhi 24, 34-37.

Wen, J., Li, S., Zheng, C., Wang, F., Luo, Y., Wu, L., et al. (2021). Tetramethylpyrazine Nitrone Improves Motor Dysfunction and Pathological Manifestations by Activating the PGC-1 $1 / \mathrm{Nrf} 2 / \mathrm{HO}-1$ Pathway in ALS Mice. Neuropharmacology 182, 108380. doi:10.1016/j.neuropharm.2020.108380

Wu, N., Xu, L., Yang, Y., Yu, N., Zhang, Z., Chen, P., et al. (2017). Tetramethylpyrazine-mediated Regulation of Cxcr4 in Retinoblastoma Is Sensitive to Cell Density. Mol. Med. Rep. 15, 2481-2488. doi:10.3892/ mmr.2017.6293

Wu, N., Yang, Y., Yu, N., Wu, Y., Han, X., Chen, S., et al. (2019). Tetramethylpyrazine Downregulates Transcription of the CXC Receptor 4
(CXCR4) via Nuclear Respiratory Factor-1 (Nrf-1) in WERI-Rb1 R-etinoblastoma C-ells. Oncol. Rep. 42, 1214-1224. doi:10.3892/or.2019.7233 Wu, W., Yu, X., Luo, X. P., Yang, S. H., and Zheng, D. (2013). Tetramethylpyrazine Protects against Scopolamine-Induced Memory Impairments in Rats by Reversing the Camp/pka/creb Pathway. Behav. Brain Res. 253, 212-216. doi:10.1016/j.bbr.2013.07.052

Wu, Y., Xu, Y., Gu, X., Hu, Y., and Wang, C. (2011). Molecular Mechanism of Tetramethylpyrazine to Induce Human Promyelocytic Hl-60 Leukemia Cells Differentiation. Zhongguo Zhong Yao Za Zhi 36, 3007-3011.

Xiao, H. J., Liang, H., Wang, J. B., Huang, C. Y., Wei, W. Q., Boniol, M., et al. (2011). Attributable Causes of Cancer in china: Fruit and Vegetable. Chin. J. Cancer Res. 23, 171-176. doi:10.1007/s11670-011-0171-7

Xie, C., Luo, J., Hu, H., Wang, L., Yu, P., Xu, L., et al. (2021). A Novel Danshensu/ tetramethypyrazine Derivative Attenuates Oxidative Stress-Induced Autophagy Injury via the Ampk-Mtor-Ulk1 Signaling Pathway in Cardiomyocytes. Exp. Ther. Med. 21, 118. doi:10.3892/etm.2020.9550

Xie, H. J., Zhao, J., Zhuo-Ma, D., Zhan-Dui, N., Er-Bu, A., and Tsering, T. (2019). Inhibiting Tumour Metastasis by Dqa Modified Paclitaxel Plus Ligustrazine Micelles in Treatment of Non-small-cell Lung Cancer. Artif. Cell Nanomed Biotechnol 47, 3465-3477. doi:10.1080/21691401.2019.1653900

Xu, B., Chu, F., Zhang, Y., Wang, X., Li, Q., Liu, W., et al. (2015). A Series of New Ligustrazine-Triterpenes Derivatives as Anti-tumor Agents: Design, Synthesis, and Biological Evaluation. Int. J. Mol. Sci. 16, 21035-21055. doi:10.3390/ ijms 160921035

Xu, B., Yan, W. Q., Xu, X., Wu, G. R., Zhang, C. Z., Han, Y. T., et al. (2017). Combination of Amino Acid/dipeptide with Ligustrazine-Betulinic Acid as Antitumor Agents. Eur. J. Med. Chem. 130, 26-38. doi:10.1016/ j.ejmech.2017.02.036

Xu, D., Chi, G., Zhao, C., and Li, D. (2018). Ligustrazine Inhibits Growth, Migration and Invasion of Medulloblastoma Daoy Cells by UpRegulation of Mir-211. Cell Physiol Biochem 49, 2012-2021. doi:10.1159/000493712

Xu, Q., Xia, P., Li, X., Wang, W., Liu, Z., and Gao, X. (2014). Tetramethylpyrazine Ameliorates High Glucose-Induced Endothelial Dysfunction by Increasing Mitochondrial Biogenesis. PloS one 9, e88243. doi:10.1371/ journal.pone. 0088243

Xu, S. H., Yin, M. S., Liu, B., Chen, M. L., He, G. W., Zhou, P. P., et al. (2017). Tetramethylpyrazine-2'-o-sodium Ferulate Attenuates Blood-Brain Barrier Disruption and Brain Oedema after Cerebral Ischemia/reperfusion. Hum. Exp. Toxicol. 36, 670-680. doi:10.1177/0960327116657401

Yan, S., Yue, Y. Z., Zong, Y., and Zeng, L. (2019). Tetramethylpyrazine Improves Postoperative Tissue Adhesion: A Drug Repurposing. Chin. J. Integr. Med. 25, 554-560. doi:10.1007/s11655-018-3021-3

Yan, Y., Zhao, J., Cao, C., Jia, Z., Zhou, N., Han, S., et al. (2014). Tetramethylpyrazine Promotes SH-Sy5y Cell Differentiation into Neurons through Epigenetic Regulation of Topoisomerase II $\beta$. Neuroscience 278, 179-193. doi:10.1016/j.neuroscience.2014.08.010

Yang, B., Li, H., Qiao, Y., Zhou, Q., Chen, S., Yin, D., et al. (2019). Tetramethylpyrazine Attenuates the Endotheliotoxicity and the Mitochondrial Dysfunction by Doxorubicin via 14-3-3 $\gamma / \mathrm{Bcl}-2$. Oxid Med. Cel Longev 2019, 5820415. doi:10.1155/2019/5820415

Yang, Q. H., Liang, Y., Xu, Q., Zhang, Y., Xiao, L., and Si, L. Y. (2011). Protective Effect of Tetramethylpyrazine Isolated from Ligusticum Chuanxiong on Nephropathy in Rats with Streptozotocin-Induced Diabetes. Phytomedicine 18, 1148-1152. doi:10.1016/j.phymed.2011.05.003

Yang, X. G., and Jiang, C. (2010). Ligustrazine as a Salvage Agent for Patients with Relapsed or Refractory Non-hodgkin's Lymphoma. Chin. Med. J. (Engl) 123, 3206-3211.

Yeom, G. G., Min, S., and Kim, S. Y. (2014). 2,3,5,6-tetramethylpyrazine of Ephedra Sinica Regulates Melanogenesis and Inflammation in a Uva-Induced Melanoma/keratinocytes Co-culture System. Int. Immunopharmacol 18, 262-269. doi:10.1016/j.intimp.2013.11.028

Yeung, S. F., Zhou, Y., Zou, W., Chan, W. L., and Ching, Y. P. (2022). TEC Kinase Stabilizes PLK4 to Promote Liver Cancer Metastasis. Cancer Lett. 524, 70-81. doi:10.1016/j.canlet.2021.08.038

Yi, B., Liu, D., He, M., Li, Q., Liu, T., and Shao, J. (2013). Role of the Ros/ampk Signaling Pathway in Tetramethylpyrazine-Induced Apoptosis in Gastric Cancer Cells. Oncol. Lett. 6, 583-589. doi:10.3892/ol.2013.1403 
Yi, M., Jiao, D., Qin, S., Chu, Q., Wu, K., and Li, A. (2019). Synergistic Effect of Immune Checkpoint Blockade and Anti-angiogenesis in Cancer Treatment. Mol. Cancer 18, 60. doi:10.1186/s12943-019-0974-6

Yin, J., Yu, C., Yang, Z., He, J. L., Chen, W. J., Liu, H. Z., et al. (2011). Tetramethylpyrazine Inhibits Migration of Skov3 Human Ovarian Carcinoma Cells and Decreases the Expression of Interleukin-8 via the Erk1/2, P38 and Ap-1 Signaling Pathways. Oncol. Rep. 26, 671-679. doi:10.3892/or.2011.1334

Yu, K., Chen, Z., Pan, X., Yang, Y., Tian, S., Zhang, J., et al. (2012). Tetramethylpyrazine-mediated Suppression of C6 Gliomas Involves Inhibition of Chemokine Receptor Cxcr4 Expression. Oncol. Rep. 28, 955-960. doi:10.3892/or.2012.1866

Yuan, X. P., Liu, L. S., Fu, Q., and Wang, C. X. (2012). Effects of Ligustrazine on Ureteral Obstruction-Induced Renal Tubulointerstitial Fibrosis. Phytother Res. 26, 697-703. doi:10.1002/ptr.3630

Zhang, C., Shen, M., Teng, F., Li, P., Gao, F., Tu, J., et al. (2018). Ultrasoundenhanced Protective Effect of Tetramethylpyrazine via the Ros/hif-1a Signaling Pathway in an In Vitro Cerebral Ischemia/reperfusion Injury Model. Ultrasound Med. Biol. 44, 1786-1798. doi:10.1016/j.ultrasmedbio.2018.04.005

Zhang, C., Teng, F., Tu, J., and Zhang, D. (2014). Ultrasound-enhanced Protective Effect of Tetramethylpyrazine against Cerebral Ischemia/reperfusion Injury. PloS one 9, el13673. doi:10.1371/journal.pone.0113673

Zhang, C., Yan, W., Li, B., Xu, B., Gong, Y., Chu, F., et al. (2015). A New Ligustrazine Derivative-Selective Cytotoxicity by Suppression of NF- $\mathrm{kB} / \mathrm{p} 65$ and COX-2 Expression on Human Hepatoma Cells. Part 3. Int. J. Mol. Sci. 16, 16401-16413. doi:10.3390/ijms160716401

Zhang, H., Ding, S., and Xia, L. (2021). Ligustrazine Inhibits the Proliferation and Migration of Ovarian Cancer Cells via Regulating Mir-211. Biosci. Rep. 41, BSR20200199. doi:10.1042/BSR20200199

Zhang, J., Liang, Y., Lin, Y., Liu, Y., You, Y., and Yin, W. (2016). IRE1a-TRAF2ASK1 Pathway is Involved in CSTMP-Induced Apoptosis and ER Stress in Human Non-small Cell Lung Cancer A549 Cells. Biomed. Pharmacother. 82, 281-289. doi:10.1016/j.biopha.2016.04.050

Zhang, P., Pei, Y., and Qi, Y. (1999). Influence of Blood-Activating Drugs on Adhesion and Invasion of Cells in Lung Cancer Patients. Zhongguo Zhong Xi Yi Jie He Za Zhi 19, 103-105.

Zhang, P., Zheng, B. B., Wang, H. Y., Chen, J. H., Liu, X. Y., and Guo, X. L. (2014). Dlj14, a Novel Chemo-Sensitization Agent, Enhances Therapeutic Effects of Adriamycin against Mcf-7/a Cells Both In Vitro and In Vivo. J. Pharm. Pharmacol. 66, 398-407. doi:10.1111/jphp.12168

Zhang, Y., Liu, X., Zuo, T., Liu, Y., and Zhang, J. H. (2012). Tetramethylpyrazine Reverses Multidrug Resistance in Breast Cancer Cells through Regulating the Expression and Function of P-Glycoprotein. Med. Oncol. 29, 534-538. doi:10.1007/s12032-011-9950-8

Zhao, H., Zhu, C., Li, X., Dong, X., Zhuang, F., Wang, X., et al. (2000). Tetramethylpyrazine Inhibits Phytohemagglutinin-Induced Upregulation of Icam-1 and Lfa-1 Mediated Leukocyte Adhesion. Clin. Hemorheol. Microcirc. 23, 145-151.

Zheng, C. Y., Xiao, W., Zhu, M. X., Pan, X. J., Yang, Z. H., and Zhou, S. Y. (2012). Inhibition of Cyclooxygenase-2 by Tetramethylpyrazine and its Effects on A549 Cell Invasion and Metastasis. Int. J. Oncol. 40, 2029-2037. doi:10.3892/ ijo. 2012.1375
Zhou, C., Shen, P., and Cheng, Y. (2007). Quantitative Study of the Drug Efflux Kinetics from Sensitive and Mdr Human Breast Cancer Cells. Biochim. Biophys. Acta 1770, 1011-1020. doi:10.1016/j.bbagen.2007.02.011

Zhou, Q., Chen, S., Li, H., Yang, B., Chen, T., Hu, T., et al. (2020). Tetramethylpyrazine Alleviates Iron Overload Damage in Vascular Endothelium via Upregulating Ddahii Expression. Toxicol. Vitro 65, 104817. doi:10.1016/j.tiv.2020.104817

Zhou, X., Wang, A., Wang, L., Yin, J., Wang, L., Di, L., et al. (2019). A DanshensuTetramethylpyrazine Conjugate Dt-010 Overcomes Multidrug Resistance in Human Breast Cancer. Front. Pharmacol. 10, 722. doi:10.3389/ fphar.2019.00722

Zhou, Y., Ji, Z., Yan, W., Zhou, Z., Li, H., and Xiao, Y. (2017). Tetramethylpyrazine Inhibits Prostate Cancer Progression by Downregulation of Forkhead Box M1. Oncol. Rep. 38, 837-842. doi:10.3892/or.2017.5768

Zhou, Y., Zhou, Z., Ji, Z., Yan, W., Li, H., and Yu, X. (2020). Tetramethylpyrazine Reduces Prostate Cancer Malignancy through Inactivation of the DPP10-AS1/ CBP/FOXM1 S-ignaling P-athway. Int. J. Oncol. 57, 314-324. doi:10.3892/ ijo. 2020.5036

Zou, J., Gao, P., Hao, X., Xu, H., Zhan, P., and Liu, X. (2018). Recent Progress in the Structural Modification and Pharmacological Activities of Ligustrazine Derivatives. Eur. J. Med. Chem. 147, 150-162. doi:10.1016/ j.ejmech.2018.01.097

Zou, L., Liu, X., Li, J., Li, W., Zhang, L., Fu, C., et al. (2021). Redox-sensitive Carrierfree Nanoparticles Self-Assembled by Disulfide-Linked PaclitaxelTetramethylpyrazine Conjugate for Combination Cancer Chemotherapy. Theranostics 11, 4171-4186. doi:10.7150/thno.42260

Zou, L., Liu, X., Li, J., Li, W., Zhang, L., Li, J., et al. (2019). Tetramethylpyrazine Enhances the Antitumor Effect of Paclitaxel by Inhibiting Angiogenesis and Inducing Apoptosis. Front. Pharmacol. 10, 707. doi:10.3389/ fphar.2019.00707

Zou, Y., Zhao, D., Yan, C., Ji, Y., Liu, J., Xu, J., et al. (2018). Novel LigustrazineBased Analogs of Piperlongumine Potently Suppress Proliferation and Metastasis of Colorectal Cancer Cells In Vitro and In Vivo. J. Med. Chem. 61, 1821-1832. doi:10.1021/acs.jmedchem.7b01096

Conflict of Interest: The authors declare that the research was conducted in the absence of any commercial or financial relationships that could be construed as a potential conflict of interest.

Publisher's Note: All claims expressed in this article are solely those of the authors and do not necessarily represent those of their affiliated organizations, or those of the publisher, the editors, and the reviewers. Any product that may be evaluated in this article, or claim that may be made by its manufacturer, is not guaranteed or endorsed by the publisher.

Copyright $\odot 2021$ Yang, Wu, Dai, Pang, Xie, Ren, Zhang, Bi, Zheng, Wang, Sun, Zheng and Kong. This is an open-access article distributed under the terms of the Creative Commons Attribution License (CC BY). The use, distribution or reproduction in other forums is permitted, provided the original author(s) and the copyright owner(s) are credited and that the original publication in this journal is cited, in accordance with accepted academic practice. No use, distribution or reproduction is permitted which does not comply with these terms. 